\title{
The flora of vascular plants in Deoksesan Mt. and its adjacent areas (Inje, Gangwon)
}

\author{
Kyung-Ah KIM, Ah-Reum GO ${ }^{1}$, Yun-Sun LEE ${ }^{1}$, Kyeong-Sik CHEON ${ }^{2}$ and Ki-Oug YOO ${ }^{1 *}$
}

\author{
Institute of Environmental Research, Kangwon National University, Chuncheon 24341, Korea \\ ${ }^{1}$ Department of Biological Sciences, Kangwon National University, Chuncheon 24341, Korea \\ ${ }^{2}$ Department of Biological Science, Sangji University, Wonju 26339, Korea \\ (Received 16 September 2020; Revised 11 May 2021; Accepted 28 May 2021)
}

\begin{abstract}
The flora of the vascular plants in Deoksesan Mt. and its adjacent areas, located at Inje-gun, Gangwon province, were surveyed for a total ten times from April of 2018 to July of 2020. The result of this survey revealed 457 taxa, consisting of 90 families, 287 genera, 404 species, 13 subspecies, 35 varieties, and 5 forms. Among them, 12 taxa were endemic plants to Korea, and 7 taxa were rare plants. Red list plants and those designated as controlled Korean biological resources, requiring special permission for export outside of the county, numbered 3 and 103 taxa, respectively. The floristic target species amounted to 83 taxa, specifically 8 taxa of grade IV, 26 taxa of grade III, 21 taxa of grade II, and 28 taxa of grade I. In addition, 14 taxa were classified as plants adaptable to climate change, and 4 taxa at their respective northern limits, first recorded in this study, were also investigated. Twenty-nine taxa of alien plants and 4 taxa of ecosystem disturbance species were also found in this area. Our results suggest that some species should be preserved and can serve as basic information with which to establish data on the preservation of resources, such as plant diversity and distributional changes on Deoksesan Mt.
\end{abstract}

Keywords: Deoksesan Mt., endemic plants, rare plants, floristic target species, alien plants

덕세산 $(747 \mathrm{~m})$ 이 위치한 강원도 인제군은 영서북부 지방에 포함되며, 지리적으로는 북위 $37^{\circ} 49^{\prime}-38^{\circ} 30^{\prime}$, 동 경 $127^{\circ} 58^{\prime}-128^{\circ} 31^{\prime}$ 에 놓여있다. 인제군의 총 면적은 $1,646 \mathrm{~km}^{2}$ 로 강원도 전체의 $10 \%$ 에 달하며, 동쪽으로는 고성군과 속초시가 위치하고 있고, 서쪽으로는 양구군 과 춘천시, 남쪽으로는 홍천군, 그리고 북쪽으로는 비 무장지대가 인접해있다. 지난 10년(2009-2018년)간 인 제군의 연평균 최고 기온과 최저 기온은 각각 $11.2^{\circ} \mathrm{C}$ 와 $9.4^{\circ} \mathrm{C}$ 였고, 연평균 강수량은 $1,196.2 \mathrm{~mm}$ 로 주로 여름철 (6-8월)에 연강수량의 $70 \%$ 이상이 집중된다(Inje-gun, 2020). 인제군은 총 면적의 $90 \%$ 이상이 산지로 구성된 산간고냉지 지대로 설악산 $(1,708 \mathrm{~m})$, 점봉산 $(1,426 \mathrm{~m})$, 방태산 $(1,436 \mathrm{~m})$, 대암산 $(1,313 \mathrm{~m})$ 등 고산을 비롯하여 내린천, 인북천, 미산 계곡 등 우수한 자연 자원을 보유 하고 있어 이 지역 자연 생태계도 비교적 잘 보전되어 있는 것으로 알려져 있다(Inje-gun, 2020).

덕세산은 한반도 식물의 지리적 분포를 바탕으로 구
분된 8개 식물구계 중 중부아구에 해당하며(Lee and Yim, 2002), 한반도 기후를 바탕으로 한 5개 산림대 중 에는 냉온대남부에 속한다(Yim and Kira, 1975). 행정구 역상으로는 강원도 인제군 서화면에 속하고, 동쪽으로 는 매봉산 $(1,271 \mathrm{~m})$, 서쪽으로는 대암산, 그리고 북쪽으 로는 수리봉 $(760 \mathrm{~m})$ 과 맞닿아 있다. 서화면은 인제군 최북단 지역으로 휴전선과 인접하며 북쪽에는 미수복 지구가 위치하고, 행정구역 대부분이 무산 $(1,320 \mathrm{~m})$, 칠 절봉 $(1,172 \mathrm{~m})$, 가칠봉 $(1,242 \mathrm{~m})$, 대암산 등 험준한 산지 로 둘러싸여 있다.

이 지역에 대한 식물상 연구는 고층습원이 있어 생태 계 측면에서의 중요성이 인정되고 있는 대암산에 대한 연구가 대부분을 차지하고 있으며(Lee, 1969; Kang, 1970; Park, 1973; Choi and Koh, 1989; Min et al., 2000; Kim et al., 2005; Ryou and Kim, 2006; Choung et al., 2009; Wonju Regional Environmental Administration, 2009), 이 외에도 원대리의 자연습지(Park et al., 2000), 민통선 접

*Author for correspondence: yooko@kangwon.ac.kr 
경지역(Lee et al., 1998; Park et al., 2001), 심적리의 이탄 습원(Kim et al., 2011), 도솔산 일대(Kim et al., 2014), 그 리고 명당산 주변(Song et al., 2019) 등에 대한 연구가 수 행된 바 있으나, 덕세산에 대한 직접적인 식물상 조사 는 이루어진 바 없다.

본 연구는 덕세산 일대의 관속식물 자원을 조사하여 이들의 분포와 특징을 밝히고, 그 결과를 식물 다양성 보전과 분포 변화 연구 등을 위한 기초 자료로 활용하 게 하고자 한다.

\section{재료 및 방법}

현지조사는 2018년 4월부터 2020년 7월까지 총 10회 에 걸쳐 수행하였고, 이에 대한 조사 경로와 일정은 Fig. 1 및 Table 1과 같다. 조사는 정확한 동정을 위하여 꽃이나 열매 등 생식기관이 있는 개체를 중심으로 채집하였으며, 수집된 자료는 건조 후 표본으로 제작하여 강원대학교 생명과학과 식물표본관(KWNU)에 보관하였고, 이를 기 초로 식물목록(Appendix 1)을 작성하였다. 식물의 동정은

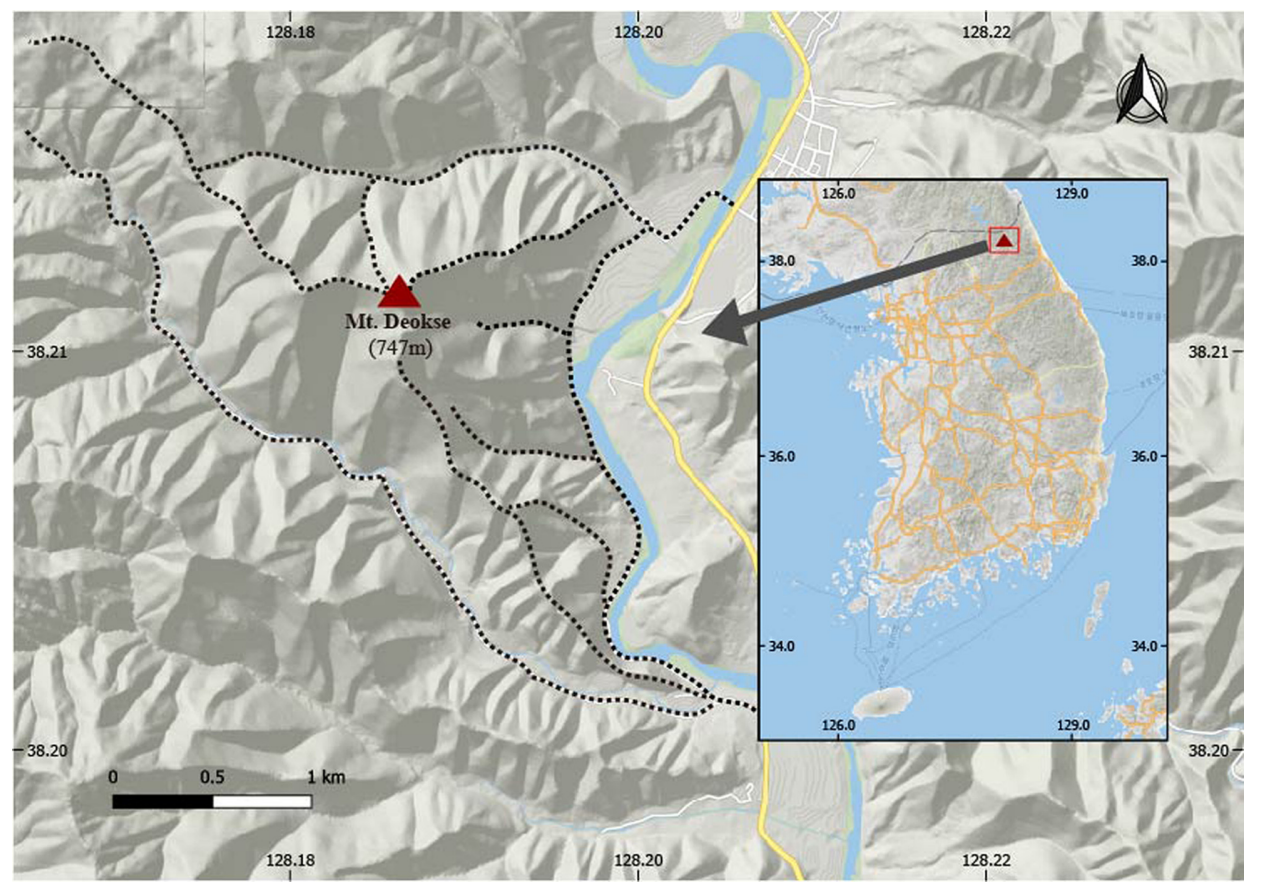

Fig. 1. Map of investigation routes of Deoksesan Mt. and its adjacent areas.

Table 1. The dates and routes of investigations.

\begin{tabular}{|c|c|c|c|}
\hline No. & & Date & Investigation routes \\
\hline 1 & 6 & Apr 2018 & Nonjang-gyo (bridge) $\rightarrow$ Yongneup-gil $\rightarrow$ Yongneup pension $\rightarrow$ Inbuk stream $\rightarrow$ Cheondoyangji-gil $\rightarrow$ Yangji-gyo (bridge) \\
\hline 2 & 7 & May 2018 & Seoheung 1-ri $\rightarrow$ Yongneup-gil $\rightarrow$ Hudong-gyo (bridge) $\rightarrow$ Summit $\rightarrow$ Cheondoyangji-gil $\rightarrow$ Yangji-gyo (bridge) \\
\hline 3 & 30 & Jun 2018 & $\begin{array}{l}\text { Nonjang-gyo (bridge) } \rightarrow \text { Yangji-gyo (bridge) } \rightarrow \text { Cheondoyangji-gil } \rightarrow \text { Iseuryangji pension } \rightarrow \text { Summit } \\
\rightarrow \text { Hudong-gyo (bridge) } \rightarrow \text { Yongneup-gil } \rightarrow \text { Seoheung 1-ri }\end{array}$ \\
\hline 4 & 22 & Jul 2018 & Seoheung 1-ri $\rightarrow$ Yongneup-gil $\rightarrow$ Hudong-gyo (bridge) $\rightarrow$ Summit $\rightarrow$ Cheondoyangji-gil $\rightarrow$ Yongneup-gil \\
\hline 5 & 10 & Aug 2018 & Seoheung 1-ri $\rightarrow$ Yongneup-gil $\rightarrow$ Yongneup farm $\rightarrow$ Dwitgol valley \\
\hline 6 & 30 & Sep 2018 & $\begin{array}{l}\text { Nonjang-gyo (bridge) } \rightarrow \text { Geumgang-ro } \rightarrow \text { Yongneup-gil } \rightarrow \text { Yongneup pension } \rightarrow \text { Inbuk stream } \rightarrow \text { Summit } \\
\rightarrow \text { Cheondoyangji-gil } \rightarrow \text { Yangji-gyo (bridge) }\end{array}$ \\
\hline 7 & 21 & Apr 2019 & $\begin{array}{l}\text { Seoheung 1-ri } \rightarrow \text { Yongneup-gil } \rightarrow \text { Hudong-gyo (bridge) } \rightarrow \text { Summit } \rightarrow \text { Iseuryangji pension } \rightarrow \text { Cheondoyangji-gil } \\
\rightarrow \text { Yangji-gyo (bridge) }\end{array}$ \\
\hline 8 & 21 & Aug 2019 & $\begin{array}{l}\text { Nonjang-gyo (bridge) } \rightarrow \text { Geumgang-ro } \rightarrow \text { Yongneup-gil } \rightarrow \text { Yongneup pension } \rightarrow \text { Inbuk stream } \rightarrow \text { Summit } \\
\rightarrow \text { Cheondoyangji-gil } \rightarrow \text { Yangji-gyo (bridge) }\end{array}$ \\
\hline 9 & 22 & May 2020 & Seoheung 1-ri $\rightarrow$ Yongneup-gil $\rightarrow$ Yongneup farm $\rightarrow$ Dwitgol valley \\
\hline 10 & 24 & Jul 2020 & Seoheung 1-ri $\rightarrow$ Yongneup-gil $\rightarrow$ Hudong-gyo (bridge) $\rightarrow$ Summit $\rightarrow$ Cheondoyangji-gil $\rightarrow$ Yongneup-gil \\
\hline
\end{tabular}


Lee (1996), Lee (2003), Lee (2006), Korea National Arboretum (2008a), 그리고 Lee and Lee (2015) 등의 도감을 이용하였 으며, 학명 및 분류체계는 국가표준식물목록(Korean National Arboretum, 2017)을 따랐고, 재배종의 경우는 국 명 뒤에 (재) 표시를 넣어 구분하였다. 작성된 식물을 바 탕으로 한국특산식물(Chung et al., 2017), 희귀식물 (Korean National Arboretum, 2008b), 적색목록식물(National Institute of Biological Resources, 2012), 국외반출 승인대상 생물자원(Ministry of Environment, 2019), 그리고 식물구계 학적 특정식물종(National Institute of Ecology, 2018)에 대해 분석하였다. 또한 기후변화 적응 대상식물은 Korea National Arboretum (2010)을 참고하였고, 남방한계 및 북 방한계 식물의 분포는 Korea National Arboretum (2016)의 자료를 이용하였다. 외래식물과 생태계교란야생종은 Kang et al. (2020)과 Infomation of Korean Alien Species (2020)의 문헌을 참고하였으며, 귀화율(Numata, 1975)과 도시화지수(Yim and Jeon, 1980)는 아래와 같은 공식을 이 용하여 산출하였다. 한편, 본 연구에서는 덕세산에 대한 식물상 자료가 전무한 관계로, 인근지역과의 비교를 위 해 대암산(Wonju Regional Environmental Administration, 2009), 도솔산(Kim et al., 2014), 그리고 명당산(Song et al., 2019)의 식물상 연구 결과를 참고하였으며, 이 중 식물 목 록의 확보가 가능한 대암산(Wonju Regional Environmental Administration, 2009)과 도솔산(Kim et al., 2014) 자료에 대 해서는 새롭게 개정된 국가표준식물목록(Korean National Arboretum, 2017)을 적용하여 그 결과를 비교하였다.

- 귀화율(the percent of naturalized plant species, PN)

$=\mathrm{S} / \mathrm{N} \cdot \mathrm{V} \times 100$

(S: 조사된 귀화식물 분류군 수; $\mathrm{N} \cdot \mathrm{V}$ : 조사된 관속식 물 총 분류군 수)

- 도시화지수(urbanization index, UI) $=\mathrm{S} / \mathrm{N} * 100$

(S: 조사된 귀화식물 분류군 수; $\mathrm{N}$ : 우리나라의 귀화 식물 총 분류군 수)

\section{결과 및 고찰}

증거표본에 근거한 덕세산 일대의 관속식물은 90 과
287속 404종 13아종 35변종 5품종으로 총 457분류군이 었으며(Table 2, Appendix 1), 이는 한반도 관속식물 4,362분류군(Korea National Arboretum, 2017)의 10.5\%, 강원도 관속식물 1,796 분류군(Gangwon-do, 2010)의 $25.4 \%$, 그리고 인제군 관속식물 1,124 분류군(Gangwondo, 2010)의 $40.7 \%$ 에 해당한다. 분류군별로는 양치식물 이 29 분류군 $(6.3 \%)$, 나자식물이 3 분류군 $(0.7 \%)$, 피자식 물은 425 분류군 $(93.0 \%)$ 으로 이 중 쌍자엽식물은 357 분 류군(78.1\%), 단자엽식물은 68분류군(14.9\%)으로 나타 났다(Table 2). 과별 구성 종에 의한 다양성은 국화과 (Compositae)가 52분류군으로 가장 많았으며, 다음으로 장미과(Rosaceae) 32분류군, 벼과(Poaceae) 26분류군, 콩 과(Fabaceae)와 백합과(Liliaceae)가 각각 19분류군, 그 리고 꿀풀과(Lamiaceae)가 18 분류군 등의 순이었다. 이 결과는 조사 지역과 인접한 대암산 464 분류군(Wonju Regional Environmental Administration, 2009)의 98.5\%, 도솔산 506분류군(Kim et al., 2014)의 $90.3 \%$, 그리고 명 당산 405분류군(Song et al., 2019)의 $112.8 \%$ 로 대암산과 도솔산 보다는 적고, 명당산 보다는 많은 수이다. 그 이 유는 대암산과 도솔산은 천연·습지 보호구역 및 민간인 통제구역 내에 위치해 훼손 정도가 상대적으로 낮은 반 면, 명당산은 군사 훈련의 목적으로 입산이 금지되어 조사를 위한 다양한 경로의 접근이 불가능하고, 산림 내 곳곳에 헬기장 또는 참호 등과 같은 군사 시설물로 인 한 훼손 면적이 비교적 넓기 때문인 것으로 생각된다. 한편 덕세산은 보호구역과 매우 인접한 동시에 해당 지 역 면소재지와 가장 가까운 산림 지역으로 453 번 지방 도를 통해 접근이 가능하고, 최근 조성된 백두대간트레 일 인제 1 구간을 지나는 등산객의 출입이 빈번하며, 서 화리, 서흥리 및 천도리에서 출입하는 임도로 둘러싸여 있어 민가 및 임도변을 중심으로 한 교란이 진행되고 있어, 앞으로 이 지역에 가해지는 인위적인 영향은 점 점 더 증가할 것으로 판단되므로 생물 자원의 지속 가 능한 보존을 위해서는 다각적인 측면에서의 관리 방안 을 모색해야 할것으로 생각된다. 대암산(Wonju Regional Environmental Administration, 2009)과 도솔산(Kim et al., 2014) 식물상 연구에서 공통적으로 조사되었으나, 덕세

Table 2. The summary of vascular plants in Deoksesan Mt. and its adjacent areas.

\begin{tabular}{lccccccc}
\hline \hline \multicolumn{1}{c}{ Taxa } & Family & Genus & Species & Subspecies & Variety & Forma & Total, $\mathrm{n}(\%)$ \\
\hline Pteriodophyta & 12 & 19 & 27 & - & 2 & - & $29(6.3)$ \\
Gymnospermae & 1 & 2 & 3 & - & - & - & $3(0.7)$ \\
Angiospermae & 77 & 266 & 374 & 13 & 33 & 5 & $425(93.0)$ \\
Dicotyledonae & 68 & 219 & 315 & 12 & 26 & 4 & $357(78.1)$ \\
Monocotyledonae & 9 & 47 & 59 & 1 & 7 & 1 & $68(14.9)$ \\
Total & 90 & 287 & 404 & 13 & 35 & 5 & $457(100)$ \\
\hline
\end{tabular}


Table 3. The list of the endemic plants in Deoksesan Mt. and its adjacent areas.

\begin{tabular}{ll}
\hline \hline \multicolumn{1}{c}{ Family name } & \multicolumn{1}{c}{ Scientific name and Korean name } \\
\hline Salicaceae & Salix koriyanagi Kimura ex Goerz 키버들 \\
Ulmaceae & Celtis choseniana Nakai 검팽나무 \\
Ranunculaceae & Aconitum pseudolaeve Nakai 진범 \\
& Clematis trichotoma Nakai 할미밀망 \\
& Thalictrum actaeifolium Siebold \& Zucc. 은꿩의다리 \\
Papaveraceae & Corydalis maculata B. U. Oh \& Y. S. Kim 점현호색 \\
Saxifragaceae & Chrysosplenium epigealum J. W. Han \& S. H. Kang 기는괭이눈 \\
Fabaceae & Vicia chosenensis Ohwi 노랑갈퀴 \\
Lamiaceae & Salvia chanryoenica Nakai 참배암차즈기 \\
Caprifoliaceae & Weigela subsessilis (Nakai) L. H. Bailey 병 꽃나무 \\
Campanulaceae & Adenophora racemosa J. K. Lee \& S. T. Lee 외대잔대 \\
Liliaceae & Heloniopsis koreana Fuse 처녀치마 \\
\hline
\end{tabular}

산에서 조사되지 않은 종류는 대부분 그늘진 습지 또는 고산 지역에 제한적으로 분포하는 종류들로 뱀톱 [Huperzia serrata (Thunb.) Trevis.], 갈퀴현호색(Corydalis grandicalyx B. U. Oh \& Y. S. Kim), 고산구슬붕이 (Gentiana wootchuliana W. K. Paik), 꽃개회나무[Syringa villosa subsp. wolfii (C. K. Schneid.) Y. Chen \& D. Y. Hong], 댕댕이나무(Lonicera caerulea L.) 등 90분류군이 었고, 이는 산림 습지의 부재와 정상부의 고도 차이에 기인한 것으로 판단된다. 이에 비해 본 조사 지역에서 만 확인된 종류는 총 126분류군으로 검팽나무(Celtis choseniana Nakai), 끈끈이장구채(Silene koreana Kom.), 은꿩의다리(Thalictrum actaeifolium Siebold \& Zucc.), 쥐 방울덩굴(Aristolochia contorta Bunge), 기는괭이눈 (Chrysosplenium epigealum J. W. Han \& S. H. Kang) 등 분 류학적으로 의미가 있는 종류와 댑싸리[Bassia scoparia (L.) A. J. Scott], 말냉이(Thlaspi arvense L.) 둥근잎나팔 꽃[Ipomoea purpurea (L.) Roth], 단풍잎돼지풀 (Ambrosia trifida L.), 쥐보리(Lolium multiflorum Lam.) 등 많은 종류 의 귀화식물이 포함되어 있었다.

한편, 본 조사 지역의 전체적인 식생은 우리나라에서 상대적으로 북쪽 지역에 형성되는 굴참나무(Quercus variabilis Blume)림이 우세하였으며(Choung, 1998), 국 소적으로는 신갈나무(Quercus mongolica Fisch. ex Ledeb.), 소나무(Pinus densiflora Siebold \& Zucc.), 박달 나무(Betula schmidtii Regel), 느릅나무[Ulmus davidiana var. japonica (Rehder) Nakai], 피나무(Tilia amurensis Rupr.)군락 등이 자주 출현하였다.

\section{한국특산식물}

본 연구에서 확인된 한국특산식물은 진범(Aconitum pseudolaeve Nakai), 할미밀망(Clematis trichotoma Nakai), 노랑갈퀴(Vicia chosenensis Ohwi), 참배암차즈기(Salvia chanryoenica Nakai), 외대잔대(Adenophora racemosa J. K. Lee \& S. T. Lee) 등 12분류군으로(Table 3), 우리나라 특 산식물 360분류군(Chung et al., 2017)의 3.3\%에 해당하였 으며, 주변 지역인 대암산(Wonju Regional Environmental Administration, 2009)의 27분류군과 도솔산(Kim et al., 2014)의 22분류군에 비해서는 적었고, 명당산(Song et al., 2019)의 9분류군에 비해서는 많았다. 대암산(Wonju Regional Environmental Administration, 2009)과 도솔산(Kim et al., 2014) 연구에서는 분포가 확인된 반면, 본 연구에서 조 사되지 않은 종류는 갈퀴현호색, 흰갱이눈(Chrysosplenium barbatum Nakai), 참좁쌀풀(Lysimachia coreana Nakai), 고산구슬붕이, 금강초롱꽃[Hanabusaya asiatica (Nakai) Nakai] 등 7 분류군으로 대부분 잘 보전된 환경을 선호 하는 종류였다. 한편, 검팽나무, 은뀡의다리, 기는괭이 눈 등 3분류군은 대암산(Wonju Regional Environmental Administration, 2009) 및 도솔산(Kim et al., 2014) 지역에 서는 조사되지 않은 종류로 본 연구를 통해 새롭게 확 인되었다. 조사된 특산식물 중 키버들(Salix koriyanagi Kimura ex Goerz)은 용늪길과 천도양지길 부근의 하천 을 따라 이어진 등산로 주변 숲 가장자리에서 조사되었 고, 검팽나무는 천도양지길에서 자연생태탐방로로 향 하는 산림 사면에서, 진범과 참배암차즈기는 용늪길에 서 정상 방향의 산림 내부에 분포하였으며, 할미밀망은 조사지 주변의 임도 사면에 생육하는 것으로 확인되었 다. 또한 은뀡의다리와 노랑갈퀴는 정상 능선부에서 조 사되었고, 점현호색(Corydalis maculata B. U. Oh \& Y. S. $\mathrm{Kim})$ 과 처녀치마(Heloniopsis koreana Fuse)는 뒷골 계곡 의 산림 사면에서, 병꽃나무[Weigela subsessilis (Nakai) 
L. H. Bailey]는 등산로 가장자리 및 인접한 산림 내에서 관찰되었으며, 외대잔대는 천도양지길에서 정상으로 향하는 산림 내부에 분포하였다. 2012년 설악산에서 최 초로 발견되어 신종으로 기재된 기는괭이눈(Han and Kang, 2012)은 동사면을 따라 조성되어 있는 자연생태 탐방로 중 산림 내부의 계곡 주변부를 따라 대규모 군 락을 형성하고 있는 것으로 확인되었는데 인위적 간섭 으로 인한 개체 수 감소의 위험은 적을 것으로 생각되 나, 계곡의 경사가 심해 장마나 태풍에 의한 수량 증가 시 자생지 유실이 우려된다.

\section{희귀식물 및 적색목록식물}

덕세산에서 확인된 희귀식물은 총 7분류군으로(Table 4), 이는 우리나라에 분포하는 전체 희귀식물 571 분류군 (Korean National Arboretum, 2008b)의 1.2\%에 해당하였으 며, 대암산(Wonju Regional Environmental Administration, 2009)의 41분류군, 도솔산(Kim et al., 2014)의 23분류군, 그리고 명당산(Song et al., 2019)의 8분류군에 비해 적게 나타났다. 본 조사에서 확인되지 않았으나, 대암산(Wonju Regional Environmental Administration, 2009) 및 도솔산(Kim et al., 2014)에서 공통적으로 조사된 종류는 금강제비꽃 (Viola diamantiaca Nakai), 참좁쌀풀, 꽃개회나무, 말나리 (Lilium distichum Nakai ex Kamib.), 나도제비란[Galearis cyclochila (Franch. \& Sav.) Soó] 등 13분류군으로 주로 높은 고도의 정상 능선부 또는 습한 서식지를 선호하는 종류였으며, 본 조사에서 새롭게 분포가 확인된 종류는 검 팽나무, 끈끈이장구채, 쥐방울덩굴 등 3 분류군이었 다. 등급별로는 멸종위기종(critically endangered, $\mathrm{CR}$ )은 끈끈이장구채 1 분류군으로 일조량이 풍부하고 척박한 임도 가장자리에 10 여 개체가 분포하는 것으로 확인되 었으며, 현재 자생지 및 개체에 가해지는 자연적인 위 협 요인은 비교적 적은 것으로 판단되나, 자생지 위치 특성상 지속적으로 가해지는 간벌 및 하예 작업 등과 같은 인위적 요인으로 인한 훼손 위험은 높은 것으로
판단된다. 약관심종(least concerned, $\mathrm{LC}$ )은 검팽나무, 쥐 방울덩굴, 도깨비부채(Rodgersia podophylla A. Gray), 참배암차즈기, 금강애기나리[Streptopus ovalis (Ohwi) F. T. Wang \& Y. C. Tang], 꽃창포[Iris ensata var. spontanea (Makino) Nakai] 등 6 분류군으로, 검팽나무는 자연생태 탐방로 주변의 산림 사면에서 소수의 개체가 확인되었 고, 쥐방울덩굴은 뒷골로 향하는 임도 및 길가 주변에 서 10 여 개체가 조사되었으며, 도깨비부채는 자연생태 탐방로와 만나는 계곡에서 대규모 군락이 관찰되었다. 또한 금강애기나리와 참배암차즈기는 정상에 이르는 산림 내부에서 각각 약 30 개체와 20 개체가 확인되었고, 꽃창포는 광량이 많은 인북천 주변에 5-10개체 정도로 구성된 소규모 군락이 간헐적으로 분포하였다. 이 중 쥐방울덩굴은 주로 도로 주변에 위치해 각종 정비 작업 의 위험에 노출되어 있었고, 꽃창포는 하천 미화 사업 및 장마철 하천 범람으로 인한 자생지 훼손이 우려된다.

한편, 적색목록식물은 총 3 분류군이었으며, 등급별 로는 관심대상 $(\mathrm{LC})$ 에 끈끈이장구채와 도깨비부채 2 분 류군, 미평가(not evaluated, $\mathrm{NE}$ )에 검팽나무 1 분류군이 었다.

\section{국외반출 승인대상 생물자원}

국외반출 승인대상 생물자원은 생물다양성 보전 측 면에서 보호 가치가 높아 국외로 반출할 경우 환경부장 관의 승인을 얻어야 하는 생물자원을 의미한다(Ministry of Environment, 2019). 본 조사를 통해 확인된 국외반출 승인대상 생물자원은 노루삼(Actaea asiatica H. Hara), 바 위떡풀(Saxifraga fortunei Hook.), 파드득나물(Cryptotaenia japonica Hassk.), 서덜취(Saussurea grandifolia Maxim.), 처 녀치마 등 총 103분류군으로(Appendix 1) 이는 국외반 출 승인 대상 생물자원 1,117분류군(Ministry of Environment, 2019)의 9.2\%에 해당하였으며, 대암산(Wonju Regional Environmental Administration, 2009)의 97분류군보다는 많았고, 도솔산(Kim et al., 2014)의 117분류군에 비해서

Table 4. The list of the rare and red list plants in Deoksesan Mt. and its adjacent areas.

\begin{tabular}{|c|c|c|c|}
\hline Family name & Scientific name and Korean name & $\mathrm{KNA}^{\mathrm{a}}$ & $\mathrm{NIBR}^{\mathrm{b}}$ \\
\hline Caryophyllaceae & Silene koreana Kom. 끈끈이장구채 & $\mathrm{CR}$ & $\mathrm{LC}$ \\
\hline Ulmaceae & Celtis choseniana Nakai 검팽나무 & LC & $\mathrm{NE}$ \\
\hline Aristolochiaceae & Aristolochia contorta Bunge 쥐방울덩굴 & LC & - \\
\hline Saxifragaceae & Rodgersia podophylla A.Gray 도깨비부채 & $\mathrm{LC}$ & $\mathrm{LC}$ \\
\hline Lamiaceae & Salvia chanryoenica Nakai 참배암차즈기 & LC & - \\
\hline Liliaceae & Streptopus ovalis (Ohwi) F. T. Wang \& Y. C. Tang 금강애기나리 & LC & - \\
\hline Iridaceae & Iris ensata var. spontanea (Makino) Nakai 꽃창포 & LC & - \\
\hline
\end{tabular}

$\overline{\mathrm{CR}}$, critically endangered; LC, least concerned; NE, not evaluated.

${ }^{a}$ Rare plants data book in Korea (Korean National Arboretum, 2008b). ${ }^{b}$ Red data book of endangered vascular plants in Korea (National Institute of Biological Resources, 2012). 
는 적었다. 본 지역에서는 분포가 확인되지 않았으나, 대암산(Wonju Regional Environmental Administration, 2009) 및 도솔산(Kim et al., 2014)에서 공통적으로 조사 된 종류는 주로 고산 및 인위적 영향이 적은 습지대에 분 포하는 범꼬리[Bistorta manshuriensis (Petrov ex Kom.) Kom.], 들바람꽃[Anemone amurensis (Korsh.) Kom.], 꿩의 바람꽃(Anemone raddeana Regel), 꽃개회나무, 두루미꽃 [Maianthemum bifolium (L.) F. W. Schmidt] 등 29분류군 이었고, 본 조사를 통해 새롭게 분포가 확인된 종류는 부싯깃고사리[Cheilanthes argentea (S. G. Gmel.) Kunze], 금뀡의다리(Thalictrum rochebrunnianum Franch. \& Sav.), 민백미꽃[Cynanchum ascyrifolium (Franch. \& Sav.) Matsum.], 송장풀(Leonurus macranthus Maxim.), 큰엉겅 퀴(Cirsium pendulum Fisch. ex DC.) 등 26분류군이었다. 조사된 국외반출 승인대상 생물자원 중 한국특산식물 은 8 분류군, 희귀식물은 4 분류군, 적색목록식물은 2 분 류군이었고, 중복되는 종류를 제외한 나머지 93분류군 은 법적보호종은 아닌 것으로 확인되었다. 그러나 이 종류들은 법적 조치와 상관 없이 국내 생물다양성 보전 과 이용에 필수적이므로 해당 조사 지역 및 국가의 유 용 자산으로 취급되어야 할 것으로 판단되며, 나아가 생물자원의 주권 확보를 위한 기초 자료로 활용되기 위 해서는 본 연구와 같은 분포 파악 등을 통해 자생지에 대한 증거 자료를 마련하고, 이에 대한 지속적인 보호 와 관심을 기울여야 할 것으로 생각된다.

\section{식물구계학적 특정종}

식물구계학적 특정종은 자연환경평가를 위한 식물 군으로 국내 주요 종의 보존 우선 순위를 결정하는데 이용되고, 특정 지역 내 이들의 분포 현황은 자연환경 의 우수성 정도를 파악하는데 유용하게 사용된다(Kim, 2000). 조사된 457분류군 중 식물구계학적 특정종은 총 83 분류군으로 전체 특정식물 1,476 분류군(National Institute of Ecology, 2018)의 5.62\%에 해당하였으며, 이는 대암 산(Wonju Regional Environmental Administration, 2009) 및 도솔산(Kim et al., 2014)에서 조사된 113분류군과 118분류 군에 비해 적었다. 대암산(Wonju Regional Environmental Administration, 2009)과 도솔산(Kim et al., 2014)에 공통 적으로 분포하나, 본 조사에서 확인되지 않은 종류는 요강나물(Clematis flabellata Nakai), 매발톱나무(Berberis amurensis Rupr.), 나도양지꽃[Waldsteinia ternata (Stephan) Fritsch], 둥근이질풀(Geranium koreanum Kom.), 솔체꽃 (Scabiosa comosa Fisch. ex Roem. \& Schult.) 등 38분류 군이었고, 덕세산에서만 분포가 확인된 종류는 개박달 나무(Betula chinensis Maxim.), 산괭이눈[Chrysosplenium japonicum (Maxim.) Makino], 황벽나무(Phellodendron amurense Rupr.), 복자기(Acer triflorum Kom.), 개현삼
(Scrophularia alata A. Gray) 등 25분류군이었다. 등급별 로는 4 개 아구 중 1 개 아구에 분포하는 IV등급에 회리 바람꽃(Anemone reflexa Steph. ex Willd.), 바위말발도리 [Deutzia grandiflora var. baroniana (Diels) Rehder], 갈기 조팝나무(Spiraea trichocarpa Nakai), 갈매나무(Rhamnus davurica Pall.), 개현삼 등 8 분류군, 2 개 아구에 분포하는 III등급에 음양고비(Osmunda claytoniana L.), 가는잎쐐 기풀(Urtica angustifolia Fisch. ex Hornem.), 노루삼, 물양 지꽃(Potentilla cryptotaeniae Maxim.), 산앵도나무[Vaccinium hirtum var. koreanum (Nakai) Kitam.] 등 26분류군, 특이한 환경에 생육하거나 비교적 전국적으로 분포하지만 $1,000 \mathrm{~m}$ 내외의 고산 지역에 주로 분포하는 II등급에 청 나래고사리[Matteuccia struthiopteris (L.) Tod.], 애기석위 [Pyrrosia petiolosa (Christ) Ching], 세잎꿩의비름 [Hylotelephium verticillatum (L.) H.Ohba], 미역줄나무 (Tripterygium regelii Sprague \& Takeda), 노랑제비꽃 [Viola orientalis (Maxim.) W.Becker] 등 21분류군, 그리고 3개 아 구에 분포하는 I등급에 부싯깃고사리, 투구꽃(Aconitum jaluense Kom.), 노랑물봉선(Impatiens noli-tangere L.), 민백 미꽃, 큰엉겅퀴 등 28 분류군이었다(Table 5).

\section{기후변화 적응 대상식물}

조사 지역의 기후변화 적응 대상식물은 검종덩굴 (Clematis fusca Turcz.), 피나물(Hylomecon vernalis Maxim.), 는쟁이냉이(Cardamine komarovii Nakai), 돌단풍[Mukdenia rossii (Oliv.) Koidz.], 당개지치(Brachybotrys paridiformis Maxim. ex Oliv.) 등 14분류군으로(Table 6) 모두 북방계 식물에 해당하였다. 이는 전체 기후변화 적응 대상식물 200 분류군(Korea National Arboretum, 2010)의 약 7.0\%, 북방계식물 100분류군(Korea National Arboretum, 2010) 의 약 $14.0 \%$ 에 해당하는 것으로, 대암산(Wonju Regional Environmental Administration, 2009) 및 도솔산(Kim et al., 2014)에서 조사된 31분류군과 23 분류군에 비해 적 었다. 덕세산에서는 확인되지 않았으나, 대암산(Wonju Regional Environmental Administration, 2009)과 도솔산 (Kim et al., 2014)에서 분포가 확인된 부게꽃나무(Acer ukurunduense Trautv. \& C.A.Mey.), 금강제비꽃, 붉은참 반디(Sanicula rubriflora F. Schmidt ex Maxim.), 구슬댕댕 이(Lonicera vesicaria Kom.), 애기앉은부채(Symplocarpus nipponicus Makino) 등 11분류군이었고, 본 조사 지역에 서 새롭게 조사된 종류는 끈끈이장구채, 갈기조팝나무, 복자기, 큰엉겅퀴 등 4 분류군이었다. 한편, 미래 기후 변화에 의한 국내 자생 식물의 종풍부도를 추정한 Shin et al. (2018)의 연구 결과에 따르면, 남방계식물은 30\% 미만으로 감소하는 것에 비해 북방계식물은 $80 \%$ 이상 감소하는 것으로 보고된 바 있다. 따라서 다른 서식지 로의 이주가 불가능하고 기후 변화가 지속 될 경우, 북 
Table 5. The list of floristic target species in Deoksesan Mt. and its adjacent areas.

\begin{tabular}{|c|c|c|}
\hline \multirow{2}{*}{$\frac{\text { Grade }}{\text { IV }}$} & \multicolumn{2}{|c|}{ Scientific name and Korean name } \\
\hline & Anemone reflexa Steph. ex Willd. 회리바람꽃 & Rhamnus davurica Pall. 갈매나무 \\
\hline & Rodgersia podophylla A. Gray 도깨비부채 & Schizopepon bryoniifolius Maxim. 산외 \\
\hline & Deutzia grandiflora var. baroniana (Diels) Rehder 바위말말도리 & Salvia chanryoenica Nakai 참배암차즈기 \\
\hline & Spiraea trichocarpa Nakai 갈기조팝나무 & Scrophularia alata A. Gray 개현삼 \\
\hline \multirow[t]{13}{*}{ III } & Osmunda claytoniana L. 음양고비 & Potentilla cryptotaeniae Maxim. 물양지꽃 \\
\hline & Betula chinensis Maxim. 개박달나무 & Prunus sargentii Rehder 산벚나무 \\
\hline & Betula davurica Pall. 물박달나무 & Sorbaria sorbifolia (L.) A. Braun 쉬땅나무 \\
\hline & Betula schmidtii Regel 박달나무 & Spiraea chamaedryfolia L. 인가목조팝나무 \\
\hline & Urtica angustifolia Fisch. ex Hornem. 가는잎쐐기풀 & Spiraea fritschiana C. K. Schneid. 참조팝나무 \\
\hline & Silene koreana Kom. 끈끈이장구채 & Vicia chosenensis Ohwi 노랑갈퀴 \\
\hline & Actaea asiatica $H$. Hara 노루삼 & Acer mandshuricum Maxim. 복장나무 \\
\hline & Clematis fusca Turcz. 검종덩굴 & Acer triflorum Kom. 복자기 \\
\hline & Clematis heracleifolia DC. 병조희풀 & Vitis coignetiae Pulliat ex Planch. 머루 \\
\hline & Thalictrum rochebrunnianum Franch. \& Sav. 금꿩의다리 & Vaccinium hirtum var. koreanum (Nakai) Kitam. 산앵도나무 \\
\hline & Corydalis maculata B. U. Oh \& Y. S. Kim 점현호색 & Lysimachia vulgaris var. davurica (Ledeb.) R. Knuth 좁쌀풀 \\
\hline & Cardamine komarovii Nakai 는쟁이냉이 & Syringa reticulata (Blume) H. Hara 개회나무 \\
\hline & Philadelphus schrenkii Rupr. 고광나무 & Brachybotrys paridiformis Maxim. ex Oliv. 당개지치 \\
\hline \multirow[t]{11}{*}{ II } & Matteuccia struthiopteris (L.) Tod. 청나래고사리 & Phellodendron amurense Rupr. 황벽나무 \\
\hline & Polystichum braunii (Spenn.) Fée 좀나도히초미 & Euonymus pauciflorus Maxim. 회목나무 \\
\hline & Pyrrosia petiolosa (Christ) Ching 애기석위 & Tripterygium regelii Sprague \& Takeda 미역줄나무 \\
\hline & Pinus koraiensis Siebold \& Zucc. 잣나무(재) & Tilia amurensis Rupr. 피나무 \\
\hline & Lychnis cognata Maxim. 동자꽃 & Tilia mandshurica Rupr. \& Maxim. 찰피나무 \\
\hline & Schisandra chinensis (Turcz.) Baill. 오미자 & Viola orientalis (Maxim.) W. Becker 노랑제비꽃 \\
\hline & Caulophyllum robustum Maxim. 뀡의다리아재비 & Viola tokubuchiana var. takedana (Makino) F. Maek. 민둥뫼제비꽃 \\
\hline & Hylomecon vernalis Maxim. 피나물 & Circaea lutetiana subsp. quadrisulcata (Maxim.) Asch. \& Magnus \\
\hline & Hylotelephium verticillatum (L.) H. Ohba 세잎꿩의비름 & 말털이슬 \\
\hline & Mukdenia rossii (Oliv.) Koidz. 돌단풍 & Weigela florida (Bunge) A. DC. 붉은병꽃나무 \\
\hline & Sorbus commixta Hedl. 마가목(재) & Carex onoei Franch. \& Sav. 바늘사초 \\
\hline \multirow[t]{15}{*}{ I } & Cheilanthes argentea (S. G. Gmel.) Kunze 부싯깃고사리 & Pyrus ussuriensis Maxim. ex Rupr. 산돌배 \\
\hline & Onoclea interrupta (Maxim.) Ching \& P. C. Chiu 야산고비 & Spiraea pubescens Turcz. 아구장나무 \\
\hline & Juglans mandshurica Maxim. 가래나무 & Impatiens noli-tangere L. 노랑물봉선 \\
\hline & Celtis choseniana Nakai 검팽나무 & Circaea cordata Royle 쇠털이슬 \\
\hline & Ulmus davidiana var. japonica (Rehder) Nakai 느릅나무 & Eleutherococcus sessiliflorus (Rupr. \& Maxim.) S. Y. Hu 오갈피나무 \\
\hline & Achudemia japonica Maxim. 산물통이 & Syringa pubescens subsp. patula (Palib.) M. C. Chang \& X.L.Chen \\
\hline & Aconitum jaluense Kom. 투구꽃 & 털개회나무 \\
\hline & Hepatica asiatica Nakai 노루귀 & Cynanchum ascyrifolium (Franch. \& Sav.) Matsum. 민백미꽃 \\
\hline & Chloranthus japonicus Siebold 홀아비꽃대 & Lonicera maackii (Rupr.) Maxim. 괴불나무 \\
\hline & Aristolochia contorta Bunge 쥐방울덩굴 & Viburnum opulus var. calvescens (Rehder) H. Hara 백당나무 \\
\hline & Chrysosplenium japonicum (Maxim.) Makino 산괭이눈 & Adoxa moschatellina L. 연복초 \\
\hline & Deutzia glabrata Kom. 물참대 & Campanula punctata Lam. 초롱꽃 \\
\hline & Deutzia uniflora Shirai 매화말발도리 & Cirsium pendulum Fisch. ex DC. 큰엉겅퀴 \\
\hline & Filipendula glaberrima (Nakai) Nakai 터리풀 & Carex dispalata Boott 삿갓사초 \\
\hline & Malus baccata (L.) Borkh. 야광나무 & \\
\hline
\end{tabular}


Table 6. The list of plant adaptable to climate change in Deoksesan Mt. and its adjacent areas.

\begin{tabular}{llc}
\hline \hline \multicolumn{1}{c}{ Family name } & \multicolumn{1}{c}{ Scientific name and Korean name } & Source \\
\hline Osmundaceae & Osmunda claytoniana L. 음양고비 & Northern plant \\
Caryophyllaceae & Silene koreana Kom. 끈근이장구채 & Northern plant \\
Ranunculaceae & Anemone reflexa Steph. ex Willd. 회리바람꽃 & Northern plant \\
Clematis fusca Turcz. 검종덩굴 & Northern plant \\
Papaveraceae & Hylomecon vernalis Maxim. 피나물 & Northern plant \\
Brassicaceae & Cardamine komarovii Nakai 는쟁이냉이 & Northern plant \\
Saxifragaceae & Mukdenia rossii (Oliv.) Koidz. 돌단풍 & Northern plant \\
& Rodgersia podophylla A. Gray 도깨비부채 & Northern plant \\
Rosaceae & Malus baccata (L.) Borkh. 야광나무 & Northern plant \\
Aceraceae & Spiraea trichocarpa Nakai 갈기조팝나무 & Northern plant \\
& Acer mandshuricum Maxim. 복장나무 & Northern plant \\
Boraginaceae & Acer triflorum Kom. 복자기 & Northern plant \\
Asteraceae & Brachybotrys paridiformis Maxim. ex Oliv. 당개지치 & Northern plant
\end{tabular}

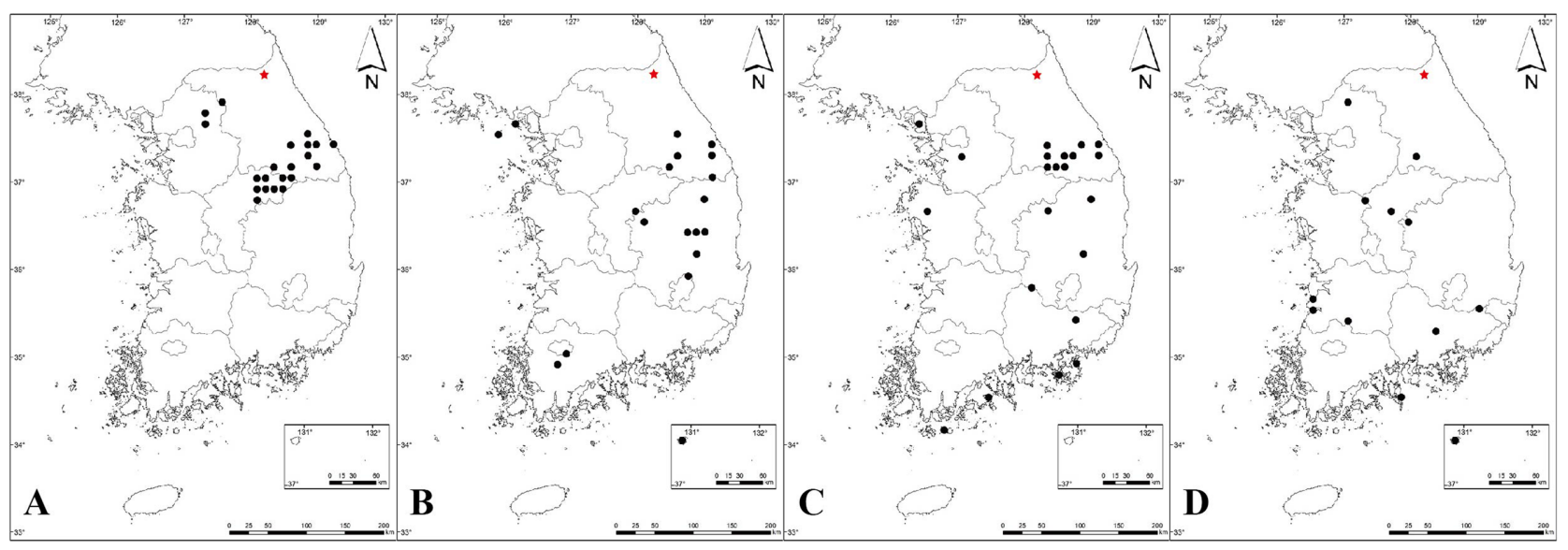

Fig. 2. Distribution maps of four plants with the northern distribution limit in Deoksesan Mt. and its adjacent areas. A. Spiraea trichocarpa Nakai. B. Pyrrosia petiolosa (Christ) Ching. C. Cheilanthes argentea (S. G. Gmel.) Kunze. D. Celtis choseniana Nakai.

방계식물이 서식하기에 적합한 자생지가 사라져 남방 계식물에 비해 상대적으로 더 큰 영향을 받을 것으로 예상되므로 생물다양성 유지를 위해서는 본 조사지와 같이 북방계식물의 분포 비율이 높은 지역을 우선적으 로 선발하여 관찰 및 관리해야 할 것으로 판단된다.

\section{남방한계 및 북방한계 식물}

조사된 식물을 바탕으로 남방한계 및 북방한계 식물 (Korea National Arboretum, 2016)을 분석한 결과, 덕세산 이 국내 분포의 북방한계인 것으로 새롭게 밝혀진 종류 는 갈기조팝나무(Fig. 2A), 애기석위(Fig. 2B), 부싯깃고 사리(Fig. 2C), 검팽나무(Fig. 2D) 등 4분류군이었고, 남
방한계인 종류는 확인되지 않았다. 갈기조팝나무는 남 양주, 삼척, 영월, 단양, 제천 등의 일부 지역에 분포하 는 것으로 보고되어 있으며(Korea National Arboretum, 2016), 덕세산에서는 동사면을 따라 조성된 자연생태탐 방로에서 정상으로 향하는 산림 내부에 10 여 개체가 자 생하는 것으로 조사되었다. 우리나라 전역의 바위 틈이 나 절벽에서 비교적 드물게 자라는 상록성 양치식물인 애기석위(Oh et al., 2013)는 기존 문헌을 통해 강화, 삼 척, 영월, 평창, 괴산 등에 분포하는 것으로 확인되었는 데(Korea National Arboretum, 2016) 본 조사 결과, 용늪 길에서 덕세산 정상으로 향하는 능선길에 위치한 바위 표면에 40-50개체가 군락을 형성하고 있는 것으로 확 
인되었다. 부싯깃고사리는 강화, 동해, 고흥, 봉화, 거제 등에 분포하며, 강원도에서는 남부 지역에 제한적으로 분포하는 것으로 알려져 있다(Korea National Arboretum, 2016). 덕세산에서는 용늪길 산림 사면에 위치한 암벽 에서 약 30 개체가 자생하는 것을 확인하였다. 주로 중 남부 지방에 생육하고, 강원도에서는 원주의 치악산에 서만 분포가 확인된 검팽나무는(Korea National Arboretum, 2016) 천도양지길 방면에서 하천 주변을 따라 자연생태 탐방로로 향하는 산림 사면에 3-4개체가 생육하였다. 이 중 애기석위와 부싯깃고사리는 주변 식물의 피압 등
과 같은 자연적인 위협 요인은 적은 것으로 판단되나, 관상 가치가 높아 실내 원예용 착생 식물로 이용되는 경우가 많아, 자생지가 노출될 경우, 인위적인 채취로 인한 개체수 감소가 우려된다. 또 검팽나무는 자생지 위치 특성 상, 생태탐방로의 정비 활동 및 유지 보수 공 사 등이 분포 개체에 큰 영향을 미칠 것으로 예상된다. 본 연구를 통해 새롭게 확인된 북방한계 식물은 학술 및 보전적 연구를 위한 기초 자료로 사용될 수 있을 뿐 만 아니라, 식물지리학적으로도 중요성을 가지고 있으 므로 특별한 관리가 필요하다고 생각된다.

Table 7. The list of alien plants in Deoksesan Mt. and its adjacent areas.

\begin{tabular}{|c|c|c|}
\hline Scientific name and Korean name & Type of alien plant & Degree \\
\hline Larix kaempferi (Lamb.) Carrière 일 본잎갈나무(재) & PIP & - \\
\hline Rumex crispus L. 소리쟁이 & IAP & WS \\
\hline Bassia scoparia (L.) A.J.Scott 댑싸리(재) & IAP & PS \\
\hline Chenopodium ficifolium $\mathrm{Sm}$. 좀명아주 & IAP & WS \\
\hline Amaranthus patulus Bertol. 가는털비름 & IAP & $\mathrm{CS}$ \\
\hline Lepidium apetalum Willd. 다닥냉이 & PIP & - \\
\hline Thlaspi arvense L. 말냉이 & Arc. & - \\
\hline Prunus persica (L.) Stokes 복사나무(재) & Arc. & - \\
\hline Robinia pseudoacacia L. 아까시나무(재) & IAP & WS \\
\hline Trifolium repens L. 토끼풀 & IAP & WS \\
\hline Euphorbia supina Raf. 애기땅빈대 & IAP & SS \\
\hline Oenothera biennis L. 달맞이꽃 & IAP & WS \\
\hline Ipomoea purpurea (L.) Roth 둥근잎나팔꽃 & IAP & $\mathrm{CS}$ \\
\hline Solanum americanum Mill. 미국까마중 & IAP & MS \\
\hline Ambrosia artemisiifolia L. 돼지풀 & IAP & WS \\
\hline Ambrosia trifida L. 단풍잎 돼지풀 & IAP & MS \\
\hline Bidens frondosa L. 미국가막사리 & IAP & WS \\
\hline Carduus crispus L. 지느러미엉겅퀴 & IAP & SS \\
\hline Conyza canadensis (L.) Cronquist 망초 & IAP & WS \\
\hline Coreopsis lanceolata L. 큰금계국(재) & IAP & $\mathrm{CS}$ \\
\hline Erigeron annuus (L.) Pers. 개망초 & IAP & WS \\
\hline Galinsoga ciliata (Raf.) S.F.Blake 털별꽃아재비 & IAP & WS \\
\hline Helianthus tuberosus L. 뚱딴지(재) & IAP & MS \\
\hline Rudbeckia laciniata L. 삼잎국화(재) & IAP & PS \\
\hline Symphyotrichum pilosum (Willd.) G. L. Nesom 미국쑥부쟁이 & IAP & SS \\
\hline Taraxacum officinale F. H. Wigg. 서양민들레 & IAP & WS \\
\hline Lolium multiflorum Lam. 쥐보리 & IAP & CS \\
\hline Panicum dichotomiflorum Michx. 미국개기장 & IAP & SS \\
\hline Phleum pratense L. 큰조아재비 & IAP & CS \\
\hline
\end{tabular}

PIP, potentially invasive plant; IAP, invasive alien plant; WS, widespread; PS, potential spread; CS, concerned spread; Arc., archaeophyte; SS, serious spread; MS, minor spread. 


\section{외래식물 및 생태계교란아생종}

조사 지역에서 확인된 외래식물은 소리쟁이(Rumex crispus L.), 가는털비름(Amaranthus patulus Bertol.), 달 맞이꽃(Oenothera biennis L.), 지느러미엉겅퀴(Carduus crispus L.), 큰조아재비(Phleum pratense L.) 등 총 29분 류군으로(Table 7), 대암산(Wonju Regional Environmental Administration, 2009)의 13분류군, 도솔산(Kim et al., 2014)의 27분류군, 그리고 명당산(Song et al., 2019)의 19 분류군에 비해 많았다. 본 조사에서 확인되지 않은 반 면, 대암산(Wonju Regional Environmental Administration, 2009)과 도솔산(Kim et al., 2014)에서 공통적으로 조사 된 종류는 주걱개망초(Erigeron strigosus Muhl. ex Willd.)와 구주개밀[Elymus repens (L.) Gould] 2분류군이 었고, 본 조사에서만 분포가 확인된 종류는 일본잎갈나 무[Larix kaempferi (Lamb.) Carrière], 아까시나무(Robinia pseudoacacia L.), 복사나무[Prunus persica (L.) Stokes], 큰금계국(Coreopsis lanceolata L.), 뚱딴지(Helianthus tuberosus L.), 삼잎국화(Rudbeckia laciniata L.) 등 11분류 군이었다. 조사된 외래식물 종류수에 의한 귀화율과 도 시화지수는 각각 $6.4 \%$ 와 $4.7 \%$ 로, 국내 산림 지역의 평 균 귀화율인 14.0\% (Oh et al., 2009)와 비교했을 때 현저 히 값이 낮았으며, 대부분 식생 도입이 제대로 이루어 지지 않은 임도 사면, 길 또는 숲 가장자리, 저지대의 등 산로 및 민가 주변 등 인위적인 간섭이 빈번한 지역에 집중적으로 생육하고 있는 것으로 나타나, 전체적인 산 림 내부에 미치는 직접적인 위해성은 크지 않은 것으로 생각된다. 조사된 외래식물을 국내 정착 및 확산 여부에 따라 구분한 결과(Kang et al., 2020), 개항(1876년) 이전에 유입된 것으로 추측되는 사전귀화식물(archaeophyte, Arc.)은 2분류군이었으며, 의도적인 도입에 의해 재배 되고 있는 종류 중 자연생태계에 확산 가능성이 있거나 분포 여부가 불확실한 잠재침입식물(potentially invasive plant, PIP)은 2분류군, 그리고 의도 또는 비의도적으로 유입되어 야생화된 침입외래식물(invasive alien plant, IAP)은 25 분류군이었다. 침입외래식물(IAP) 중 국내 확 산 정도에 따라 가장 넓은 분포를 보이는 5 등급 (widespread, WS)은 11분류군, 4등급(serious spread, SS) 은 4분류군, 3등급(concerned spread, CS)은 5분류군, 2등 급(minor spread, MS)은 3분류군, 그리고 1등급(potential spread, PS)은 2분류군이었다. 이 중 유일한 목본 식물에 해당하는 5 등급의 아까시나무는 1891 년 사방수종, 용 재, 신탄재, 밀원식물, 가로수용 등의 목적으로 식재되 었으나(Wada, 2007), 번식력이 강해 국내에 넓게 확산되 었으며, 최근에는 관리 부주의로 식재된 개체가 산림내 로 침입하여 국내 생물종을 피압하고, 생장을 억제 및 고사시키는 피해 사례가 보고 되고 있다(Jung et al., 2011). 따라서 자연 생태계에 부정적인 영향을 미칠 가
능성이 있는 침입외래식물(IAP)의 확산을 최소화하기 위해서는 재배되는 외래종이라 할지라도 예방 차원에 서 재배지 주변 식생을 모니터링하고 관리하는 것이 필 요할 것이며, 이미 토착화되었거나 소멸된 것으로 보이 는 종류도 특정 지역에서의 환경 적응 유무에 따라 분 포역은 계속 변화할 수 있으므로 지속적인 현황 파악이 필요할 것으로 생각된다. 한편, 생태계교란야생종은 우 리나라 자생식물인 환삼덩굴[Humulus scandens (Lour.) Merr.]을 포함하여 돼지풀(Ambrosia artemisiifolia L.), 단풍 잎돼지풀, 미국쑥부쟁이[Symphyotrichum pilosum (Willd.) G. L. Nesom] 등 총 4분류군이 조사되었다. 이 중 돼지풀, 단풍잎돼지풀, 미국쑥부쟁이는 산림 저지대의 가장자 리에 간헐적인 분포를 보여 조사지 생태계에 미치는 직 접적인 영향을 크지 않을 것으로 생각되나, 이러한 종 류는 전국적인 확산이 문제시 되고 있는 만큼 지속적인 모니터링을 통해 위험성을 파악해야 할 것으로 판단된 다. 특히 환삼덩굴은 주로 광조건이 좋은 저지대 또는 개활지에서 대규모 군락을 형성하고 있었으며, 추후 분 포역을 확장함과 동시에 다른 식물을 피복하여 서식 공 간을 단순화 시킬것으로 예상되므로 조사 지역의 산림 내 추가 확산을 막기 위한 적극적인 제거 및 관리가 필 요할 것으로 생각된다.

ORCID: Kyung Ah KIM https://orcid.org/0000-0001-72893950; Ah Reum GO https://orcid.org/0000-0002-6539224X; Yun Sun LEE https://orcid.org/0000-0002-05069934; Kyeong-Sik CHEON https://orcid.org/0000-00022182-7379; Ki Oug YOO https://orcid.org/0000-00022676-6878

\section{Acknowledgments}

This study was supported by the project "Research on the plants of unexplored areas within the DMZ and develop a monitoring system of intensive management species (KNA1-2-34, 18-5)" funded by the Korea National Arboretum. We would like to thank Sang-don Byeon, Jinhyeok Kim and Sang-gyun Hong for their participating in the investigation.

\section{Conflict of Interest}

The authors declare that there are no conflicts of interest.

\section{Literature Cited}

Choi, K.-R. and J.-K. Koh. 1989. Studies on moor vegetation of 
Mt. Daeam, east-central Korea. Korean Journal of Ecology 12: 237-244. (in Korean)

Choung, Y. S. 1998. Vegetation in the paekdoo great mountain chain. Journal of Environmenta Research 15: 464-470. (in Korean)

Choung, Y. S., W. T. Lee, K. Y. Joo, J. S. Lee, H. S. Seo, K. E. Lee and A. N. Seo. 2009. Review on the herbaceous flora of Keunyongneup in Mt. Daeam, Korea. Journal of Basic Science Research Institute 20: 205-227. (in Korean)

Chung, G. Y., K. S. Chang, J.-M. Chung, H. J. Choi, W.-K. Paik and J.-O. Hyun. 2017. A checklist of endemic plants on the Korean Peninsula. Korean Journal of Plant Taxonomy 47: 264-288. (in Korean)

Gangwon-do. 2010. Inhabitation and Distribution of Wild Animal and Plant in Gangwon-do. Gangwon-do, 215 pp. (in Korean)

Han, J.-W. and S.-H. Kang. 2012. Chrysosplenium epigealum J. W. Han et S. H. Kang: A new species of Chrysosplenium (Saxifragaceae) from Korea. Korean Journal of Plant Resources 25: 346-348.

Infomation of Korean Alien Species. 2020. Retrieved Dec. 2, 2020, available from http://kias.nie.re.kr.

Inje-gun. 2020. Retrieved Sep. 10, 2020, available from http:// www.inje.go.kr.

Jung, S., K. Koo and K.-H. Kim. 2011. Inhibitory factors of Robinia pseudoacacia distribution in a Pinus thunbergii forest at the coast. Korean Journal of Environment and Ecology 25: 717-724. (in Korean)

Kang, E. S., S.-R. Lee, S. H. Oh, D.-K. Kim, S.-Y. Jung and D. C. Son. 2020. Comprehensive review about alien plants in Korea. Korean Journal of Plant Taxonomy 50: 89-119. (in Korean)

Kang, S. J. 1970. Ecological studies of the raised bog in the Daeam mountain adjacent to DMZ in Korea (II): Relation between vegetation and peat. Journal of Plant Biology 13: 20-24. (in Korean)

Kim, B. W., J. S. Lee and Y. J. Oh. 2005. A study on the flora in the Mt. Daeam high moor. Journal of Environmental Science 11: 1-8. (in Korean)

Kim, C. H. 2000. Assessment of natural environment: I. Selection of plant taxa. Korean Journal of Environmental Biology 18: 163-198. (in Korean)

Kim, K.-A., J.-S. Han, K.-S. Cheon, Y.-H. Park, J.-S. Kang and K.-O. Yoo. 2014. Floristic study of Mt. Dosol and its adjacent areas (Yanggu-gun, Gangwon-do). Korean Journal of Plant Taxonomy 44: 59-76. (in Korean)

Kim, N. J., N. Y. Kim, Y. S. Kim, H. B. Lee, Y. S. Kim and W. K. Park. 2011. Flora Study of Simjeok Swamp in Sohwa-myon, Inje-gun. Korean Forest Society, Seoul. Pp. 374-376. (in Korean)
Korea National Arboretum. 2008a. Illustrated Pteridophytes of Korea. Korea National Arboretum, Pocheon, 547 pp. (in Korean)

Korea National Arboretum. 2008b. Rare Plants Data Book in Korea. Korea National Arboretum, Pocheon, 547 pp. (in Korean)

Korea National Arboretum. 2010. 300 Target Plants Adaptable to Climate Change in the Korean Peninsula. Korea National Arboretum, Pocheon, 492 pp. (in Korean)

Korea National Arboretum. 2016. Distribution Maps of Vascular Plants in Korea. Korea National Arboretum, Pocheon, 809 pp. (in Korean)

Korea National Arboretum. 2017. Checklist of Vascular Plant in Korea. Korea National Arboretum, Pocheon, 1000 pp. (in Korean)

Lee, C. S. and K. H. Lee. 2015. Pteridophytes of Korea: Lycophytes \& Ferns. Geobook, Seoul, 471 pp. (in Korean)

Lee, H. J., B. H. Bae, Y. M. Chun, H. L. Chung, M. P. Hong, Y. O. Kim and J. H. Kil. 1998. Community structure and soil environment of Quercus mongolica forest on Mt. Chiljelbong. Journal of Basic Science 23: 83-95. (in Korean)

Lee, T. B. 2003. Coloured Flora of Korea, Vol. I, II. Hyangmunsa, Seoul, Vol. I, 914 pp, Vol. II, 910 pp. (in Korean)

Lee, W. T. 1996. Coloured Standard Illustrations of Korean Plants. Academy Publishing Co., Seoul, 624 pp. (in Korean)

Lee, W. T. and and Y. J. Yim. 2002. Plant Geography with Special Reference to Korea. Kangwon National University Press, Chuncheon, 412 pp. (in Korean)

Lee, Y. N. 1969. Swamp plants on Mt. Dae-Am in the central part of Korea. Korean Journal of Plant Taxonomy 1: 7-14. (in Korean)

Lee, Y. N. 2006. New Flora of Korea, Vol. I, II. Kyohak Publishing Co., Seoul, Vol. I. 1975 pp, Vol. II, 2885 pp. (in Korean)

Ministry of Environment. 2019. Retrieved Dec. 7, 2020, available from http://www.me.go.kr.

Min, W. K., C. S. Chang, J. I. Jeon, H. Kim, D. Y. Choi and S. S. Jung. 2000. Flora of Mt. Dae-am san. Bulletin of Seoul National University Arboretum 20: 38-82. (in Korean)

National Institute of Biological Resources. 2012. Red Data Book of Endangered Vascular Plants in Korea. National Institute of Biological Resources, Incheon, 391 pp. (in Korean)

National Institute of Ecology. 2018. Floristic Target Species (FT Species) in Korea. National Institute of Ecology, Seocheon, 728 pp. (in Korean)

Numata, M. 1975. Naturalized Plants. Dai Nippon Printing Co. Tokyo, 160 pp. (in Japanese)

Oh, C.-H., Y.-H. Kim, H.-Y. Lee and S.-H. Ban. 2009. The naturalization index of plant around abandoned military camps in 
civilian control zone. Journal of Korean Environment Research Technology 12: 59-76. (in Korean)

Oh, H. K., J. H. Rho and Y. H. Choi. 2013. A study on the vegetation landscape and management methods of Buyongdae on Hahoe village, Andong. Journal of Korean Institute of Traditional Landscape Architecture 31: 13-27. (in Korean)

Park, B. K. 1973. On the vegetation of high-moor on Mt. Dae-am, Kangwon-do, Korea. Journal of Korean Research Institute Better Living 11: 25-32. (in Korean)

Park, K.-S., C.-H. Ahn and W.-G. Park. 2001. A study on the flora and vegetation of civilian control line area (Hyangro-Bong, Chiljeol-Bong, Mt. Mae-Bong in Inje-gun, Kangwon-do). Journal of Korea Forestry Energy 20: 81-116. (in Korean)

Park, W.-G., S.-I. Yoo and K.-S. Park. 2000. Flora of natural mashes in Wondae-ri (Inje-gun, Kangwon-do). Journal of Forest Science Kangwon National University 16: 50-68. (in Korean)

Ryou, S. H. and S. D. Kim. 2006. The flora of Young-neup and vegetation distribution of high moor in Mt. Daeam. In Proceedings of the Korean Society of Environment and Ecology Conference. Korean Society of Environment and Ecology, Seoul. Pp. 133-135. (in Korean)

Shin, M.-S., C. Seo, M. Lee, J.-Y. Kim, J.-Y. Jeon, P. Adhikari and
S.-B. Hong. 2018. Prediction of potential species richness of plants adaptable of climate change in the Korean peninsula. Journal of Environmental Impact Assessment 27: 562-581. (in Korean)

Song, J. H., S. J. Kim, J. B. An, H. S. Hwang, A. Y. Lee, G. P. Bak, J. S. Park, S. Y. Jung, J. Y. Jung and H. C. Kim. 2019. The flora of Mt. Myeongdang (Gangwon-do, Inje-gun) area adjacent to the DMZ. In 2019 Conference \& Symposium of the Korean Journal of Plant Taxonomy. Korean Society of Plant Taxonomists, Pocheon. p. 73. (in Korean)

Wada, Y. 2007. Beekeeping and black locust. Japan Forest Technology 781: 22-25.

Wonju Regional Environmental Adiministration. 2009. Yongneup in Mt. Daeam. Wonju Regional Environmental Adiministration, Wonju, $285 \mathrm{pp}$.

Yim, Y. J. and E. S. Jeon. 1980. Distribution of naturalized plants in the Korean peninsula. Korean Journal of Botany 23: 69-83. (in Korean)

Yim, Y.-J. and T. Kira. 1975. Distribution of forest vegetation and climate in the Korean Peninsula: I. Distribution of some indices of thermal climate. Japanese Journal of Ecology 25: 7788.

\title{
덕세산(인제, 강원) 일대의 관속식물상
}

\author{
김경아 · 고아름 ${ }^{1} \cdot$ 이윤순 ${ }^{1}$ 천경식 ${ }^{2} \cdot$ 유기억 $^{1 *}$ \\ 강원대학교 환경연구소, ${ }^{1}$ 강원대학교 생명과학과, ${ }^{2}$ 상지대학교 생명과학과
}

\begin{abstract}
적 요: 강원도 인제군에 위치한 덕세산 일대의 관속식물상을 2018년 4월부터 2020 년 7 월까지 총 10 회에 걸 쳐 조사하였다. 그 결과 확인된 관속식물은 90 과 287 속 404 종 13 아종 35 변종 5 품종의 총 457 분류군이었다. 이 중 한국특산식물은 12 종류였고, 희귀식물은 7 분류군, 적색목록식물은 3 분류군, 그리고 국외반출 승인대상 생물자원은 103 분류군이었다. 식물구계학적 특정식물종은 총 83 종류로 IV등급 8 분류군, III등급 26 분류군, II 등급 21 분류군, 그리고 I 등급에 28 분류군이 포함되어 있었다. 기후변화 적응 대상식물은 14 분류군이었고, 덕세산이 북방한계인 식물은 4 분류군, 외래식물은 29 분류군, 그리고 생태계교란야생종은 4 종류였다. 본 연구 결과는 보전이 필요한 주요 종들을 제시하였으며, 덕세산의 식물 다양성 및 분포 변화 연구 등의 자원 보존 을 위한 기초 자료로 활용될 것이다.
\end{abstract}

주요어: 덕세산, 특산식물, 희귀식물, 식물구계학적 특정종, 외래식물 
Appendix 1. The list of vascular plants investigated in the Deoksesan Mt. and its adjacent areas.

\begin{tabular}{l}
\hline \hline \multicolumn{1}{c}{ Scientific name/Korean name/Voucher number } \\
\hline Selaginellaceae 부처손과 \\
Selaginella rossii (Baker) Warb. 구실사리 $K W N U 94868$ \\
Equisetaceae 속새과 \\
Equisetum arvense L. 쇠뜨기 KWNU94874 \\
Osmundaceae 고비과 \\
Osmunda claytoniana L. 음양고비 KWNU94869 \\
Dennstaedtiaceae 잔고사리과 \\
Dennstaedtia hirsuta (Sw.) Mett. ex Miq. 잔고사리 KWNU94875 \\
Dennstaedtia wilfordii (T.Moore) Christ 황고사리 $K W N U 94279$ \\
Pteridium aquilinum var. latiusculum (Desv.) Underw. ex A. Heller 고 \\
사리 KWNU94972
\end{tabular}

\section{Pteridaceae 봉의꼬리과}

Cheilanthes argentea (S.G.Gmel.) Kunze 부싯깃고사리 KWNU95321 ^ Aspleniaceae 꼬리고사리과

Asplenium incisum Thunb. 꼬리고사리 KWNU94877

Asplenium ruprechtii Sa.Kurata 거미고사리 KWNU94871

Thelypteridaceae 처녀고사리과

Thelypteris palustris (A.Gray) Schott 처녀고사리 KWNU94360

Woodsiaceae 우드풀과

Woodsia manchuriensis Hook. 만주우드풀 KWNU94339

Woodsia polystichoides D.C.Eaton 우드풀 KWNU94876

Onocleaceae 야산고비과

Matteuccia struthiopteris (L.) Tod. 청나래고사리 KWNU94902

Onoclea interrupta (Maxim.) Ching \& P.C.Chiu 야산고비 KWNU94930

Pentarhizidium orientale (Hook.) Hayata 개면마 KWNU94864

\section{Athyriaceae 개고사리과}

Athyrium niponicum (Mett.) Hance 개고사리 KWNU95417

Athyrium yokoscense (Franch. \& Sav.) Christ 뱀고사리 KWNU97446

Deparia pycnosora (Christ) M.Kato 털고사리 KWNU94903

Deparia pycnosora var. albosquamata M.Kato 흰털고사리 KWNU94870

\section{Dryopteridaceae 관중과}

Arachniodes borealis Seriz. 왁살고사리 KWNU95948

Dryopteris chinensis (Baker) Koidz. 가는잎족제비고사리 KWNU94863

Dryopteris crassirhizoma Nakai 관중 KWNU94928

Dryopteris lacera (Thunb.) Kuntze 비늘고사리 KWNU94929

Polystichum braunii (Spenn.) Fée 좀나도히초미 KWNU95814

Polystichum craspedosorum (Maxim.) Diels 낚시고사리 KWNU94872

Polystichum tripteron (Kunze) C.Pres1 십자고사리 KWNU94873

Polypodiaceae 고란초과

Lepisorus ussuriensis (Regel \& Maack) Ching 산일엽초 KWNU94318 Pyrrosia linearifolia (Hook.) Ching 우단일엽 KWNU96495
Appendix 1. Continued.

\begin{tabular}{l} 
Scientific name/Korean name/Voucher number \\
\hline \hline Pyrrosia petiolosa (Christ) Ching 애기석위 KWNU97441 \\
Pinaceae 소나무과 \\
Larix kaempferi (Lamb.) Carrière 일본잎갈나무(재) KWNU95427 \\
Pinus densiflora Siebold \& Zucc. 소나무 KWNU94865 \\
Pinus koraiensis Siebold \& Zucc. 잣나무(재) KWNU97239 \\
Juglandaceae 가래나무과 \\
Juglans mandshurica Maxim. 가래나무 KWNU94886 \\
Salicaceae 버드나무과 \\
Populus tremula var. davidiana (Dode) C.K.Schneid. 사시나무 \\
KWNU96941 \\
Salix caprea L. 호랑버들 KWNU94894^ \\
Salix gracilistyla Miq. 갯버들 KWNU94911 \\
Salix koriyanagi Kimura ex Goerz 키버들 KWNU94946 \\
Salix pierotii Miq. 버드나무 KWNU94912 \\
Betulaceae 자작나무과 \\
Betula chinensis Maxim. 개박달나무 KWNU95376 \\
Betula davurica Pall. 물박달나무 KWNU94914 \\
Betula schmidtii Regel 박달나무 KWNU96930 \\
Corylus heterophylla Fisch. ex Trautv. 난티잎개암나무 KWNU97454 \\
Corylus sieboldiana Blume 참개암나무 KWNU94878 \\
Corylus sieboldiana var. mandshurica (Maxim.) C.K.Schneid. 물개암 \\
나무 KWNU94978
\end{tabular}

Fagaceae 참나무과

Castanea crenata Siebold \& Zucc. 밤나무(재) KWNU96496

Quercus aliena Blume 갈참나무 KWNU94455

Quercus dentata Thunb. 떡갈나무 KWNU94915

Quercus mongolica Fisch. ex Ledeb. 신갈나무 KWNU94315

Quercus serrata Murray 졸참나무 KWNU95957

Quercus variabilis Blume 굴참나무 KWNU94245

Ulmaceae 느릅나무과

Celtis choseniana Nakai 검 팽나무 KWNU97227

Celtis sinensis Pers. 팽나무 KWNU96933

Ulmus davidiana var. japonica (Rehder) Nakai 느릅나무 KWNU94982

Zelkova serrata (Thunb.) Makino 느티나무(재) KWNU95402* Moraceae 뽕나무과

Morus australis Poir. 산뽕나무 KWNU94471

Cannabaceae 삼과

Humulus scandens (Lour.) Merr. 환삼덩굴 KWNU95412

Urticaceae 쐐기풀과

Achudemia japonica Maxim. 산물통이 KWNU95960

Boehmeria japonica (L.f.) Miq. 왜모시풀 KWNU95271

Boehmeria spicata (Thunb.) Thunb. 좀깨잎나무 KWNU95384

Boehmeria tricuspis (Hance) Makino 거북꼬리 KWNU96504

Pilea pumila (L.) A.Gray 모시물통이 KWNU94917 
Appendix 1. Continued.

Scientific name/Korean name/Voucher number

Urtica angustifolia Fisch. ex Hornem. 가는잎쐐기풀 KWNU95962

Urtica laetevirens Maxim. 애기쐐기풀 KWNU97226

\section{Santalaceae 단향과}

Thesium chinense Turcz. 제비꿀 KWNU94918

\section{Polygonaceae 마디풀과}

Fallopia dumetorum (L.) Holub 닭의덩굴 KWNU95369

Persicaria dissitiflora (Hemsl.) H.Gross ex T.Mori 가시여뀌 KWNU95371

Persicaria hydropiper (L.) Delarbre 여뀌 KWNU95372

Persicaria japonica (Meisn.) Nakai 흰꽃여뀌 KWNU97238

Persicaria longiseta (Bruijn) Kitag. 개여뀌 KWNU94881

Persicaria nepalensis (Meisn.) H.Gross 산여뀌 KWNU95367

Persicaria perfoliata (L.) H.Gross 며느리배꼽 KWNU95375

Persicaria posumbu (Buch.-Ham. ex D.Don) H.Gross 장대여뀌 KWNU95548

Persicaria sagittata (L.) H.Gross 미꾸리낚시 KWNU94920

Persicaria senticosa (Meisn.) H.Gross ex Nakai 며느리밑씻개 KWNU94922

Persicaria thunbergii (Siebold \& Zucc.) H.Gross 고마리 KWNU94324

Polygonum aviculare L. 마디풀 KWNU97491

Rumex acetosa L. 수영 KWNU94472

Rumex crispus L. 소리쟁이 KWNU94923

Portulacaceae 쇠비름과

Portulaca oleracea L. 쇠비름 KWNU94921

Caryophyllaceae 석죽과

Arenaria serpyllifolia L. 벼룩이자리 KWNU94905

Cerastium holosteoides var. hallaisanense (Nakai) Mizush. 점나도나 물 KWNU96516

Dianthus chinensis L. 패랭이꽃 KWNU94925

Lychnis cognata Maxim. 동자꽃 KWNU94926

Pseudostellaria davidii (Franch.) Pax ex Pax \& Hoffm. 덩굴개별꽃 KWNU94927

Pseudostellaria heterophylla (Miq.) Pax 개별꽃 KWNU94945

Pseudostellaria palibiniana (Takeda) Ohwi 큰개별꽃 KWNU95939

Silene baccifera (L.) Roth 덩굴별꽃 KWNU96487

Silene firma Siebold \& Zucc. 장구채 KWNU95951

Silene koreana Kom. 끈끈이장구채 KWNU94883

Stellaria aquatica (L.) Scop. 쇠별꽃 KWNU94895

Chenopodiaceae 명아주과

Bassia scoparia (L.) A.J.Scott 댑싸리(재) KWNU95276

Chenopodium ficifolium Sm. 좀명아주 KWNU94658

Amaranthaceae 비름과

Amaranthus patulus Bertol. 가는털비름 KWNU97122

Schisandraceae 오미자과

Schisandra chinensis (Turcz.) Baill. 오미자 KWNU97488
Appendix 1. Continued.

\begin{tabular}{|c|}
\hline Scientific name/Korean name/Voucher number \\
\hline Lauraceae 녹나무과 \\
\hline Lindera obtusiloba Blume 생강나무 KWNU94349 \\
\hline Ranunculaceae 미나리아재비과 \\
\hline Aconitum jaluense Kom. 투구꽃 KWNU94662 ${ }^{\star}$ \\
\hline Aconitum pseudolaeve Nakai 진범 KWNU94664^ \\
\hline Actaea asiatica H.Hara 노루삼 $K W N U 95950^{\star}$ \\
\hline $\begin{array}{l}\text { Actaea dahurica (Turcz. ex Fisch. \& C.A.Mey.) Franch. 눈빛승마 } \\
K W N U 94667^{\star}\end{array}$ \\
\hline Anemone reflexa Steph. ex Willd. 회리바람꽃 KWNU94666 \\
\hline Clematis apiifolia DC. 사위질빵 KWNU94669 \\
\hline Clematis fusca Turcz. 검종덩굴 KWNU95388 \\
\hline Clematis heracleifolia $\mathrm{DC}$. 병조희풀 $K W N U 95001^{\star}$ \\
\hline $\begin{array}{l}\text { Clematis terniflora var. mandshurica (Rupr.) Ohwi 으아리 } \\
\text { KWNU94670 }\end{array}$ \\
\hline Clematis trichotoma Nakai 할미밀망 KWNU95003* \\
\hline Hepatica asiatica Nakai 노루귀 KWNU94671 \\
\hline 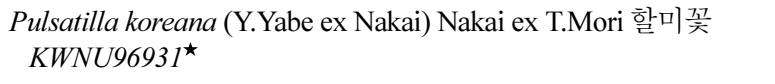 \\
\hline
\end{tabular}

Thalictrum actaeifolium Siebold \& Zucc. 은뀡의다리 KWNU96518

Thalictrum aquilegiifolium var. sibiricum Regel \& Tiling 아시아꿩의 다리 KWNU94993*

Thalictrum rochebrunnianum Franch. \& Sav. 금뀡의다리 KWNU97460*

Thalictrum tuberiferum Maxim. 산뀡의다리 KWNU94812

Berberidaceae 매자나무과

Caulophyllum robustum Maxim. 뀡의다리아재비 KWNU95968

Menispermaceae 방기과

Menispermum dauricum DC. 새모래덩굴 KWNU97456

Chloranthaceae 홀아비꽃대과

Chloranthus japonicus Siebold 홀아비꽃대 KWNU94947

Aristolochiaceae 쥐방울덩굴과

Aristolochia contorta Bunge 쥐방울덩굴 KWNU95387

Asarum sieboldii Miq. 족도리풀 KWNU97438

Actinidiaceae 다래나무과

Actinidia arguta (Siebold \& Zucc.) Planch. ex Miq. 다래 KWNU94642 ${ }^{\star}$ Actinidia polygama (Siebold \& Zucc.) Planch. ex Maxim. 개다래 KWNU95413

Clusiaceae 물레나물과

Hypericum ascyron L. 물레나물 KWNU94644

Hypericum erectum Thunb. 고추나물 KWNU94686

Papaveraceae 양귀비과

Chelidonium majus subsp. asiaticum H.Hara 애기똥풀 KWNU95408

Corydalis maculata B.U.Oh \& Y.S.Kim 점현호색 KWNU94687

Corydalis ochotensis Turcz. 눈괴불주머니 KWNU94646

Corydalis remota Fisch. ex Maxim. 현호색 KWNU94647 
Appendix 1. Continued.

\begin{tabular}{|c|}
\hline Scientific name/Korean name/Voucher number \\
\hline Corydalis speciosa Maxim. 산괴불주머니 KWNU94648 \\
\hline Hylomecon vernalis Maxim. 피나물 KWNU94645 \\
\hline Brassicaceae 십자화과 \\
\hline Barbarea orthoceras Ledeb. 나도냉이 KWNU96499 \\
\hline Berteroella maximowiczii (Palib.) O.E.Schulz 장대냉이 KWNU94649 \\
\hline Capsella bursa-pastoris (L.) Medik. 냉이 KWNU94931 \\
\hline Cardamine flexuosa With. 황새냉이 KWNU94892 \\
\hline Cardamine komarovii Nakai 는쟁이냉이 KWNU94650 \\
\hline Cardamine leucantha (Tausch) O.E.Schulz 미나리냉이 KWNU94688 \\
\hline Draba nemorosa L. 꽃다지 KWNU94891 \\
\hline Lepidium apetalum Willd. 다닥냉이 KWNU94652 \\
\hline Rorippa palustris (L.) Besser 속속이풀 KWNU95362 \\
\hline Thlaspi arvense L. 말냉이 KWNU94653 \\
\hline Crassulaceae 돌나물과 \\
\hline Hylotelephium verticillatum (L.) H.Ohba 세잎뀡의비름 KWNU95406 \\
\hline $\begin{array}{l}\text { Phedimus kamtschaticus (Fisch. \& C.A.Mey.) 't Hart 기린초 } \\
\text { KWNU94316 }\end{array}$ \\
\hline Sedum sarmentosum Bunge 돌나물 KWNU94654 $4^{\star}$ \\
\hline Saxifragaceae 범의귀과 \\
\hline Astilbe chinensis (Maxim.) Franch. \& Sav. 노루오줌 $K W N U 94689^{\star}$ \\
\hline $\begin{array}{l}\text { Chrysosplenium epigealum J.W.Han \& S.H.Kang 기는괭이눈 } \\
\text { KWNU95382 }\end{array}$ \\
\hline
\end{tabular}

Chrysosplenium flagelliferum F.Schmidt 애기괭이눈 KWNU94934 Chrysosplenium japonicum (Maxim.) Makino 산괭이눈 KWNU94897^ Mukdenia rossii (Oliv.) Koidz. 돌단풍 KWNU94374* Rodgersia podophylla A.Gray 도깨비부채 KWNU96937 Saxifraga fortunei Hook. 바위떡풀 KWNU95443 ${ }^{\star}$

Hydrangeaceae 수국과

Deutzia glabrata Kom. 물참대 KWNU94333

Deutzia grandiflora var. baroniana (Diels) Rehder 바위말발도리 KWNU94373

Deutzia uniflora Shirai 매화말발도리 KWNU94366

Philadelphus schrenkii Rupr. 고광나무 KWNU94304

Grossulariaceae 까치밥나무과

Ribes fasciculatum var. chinense Maxim. 까마귀밥나무 KWNU96814

Rosaceae 장미과

Agrimonia coreana Nakai 산짚신나물 KWNU96500

Agrimonia pilosa Ledeb. 짚신나물 KWNU97471

Crataegus pinnatifida Bunge 산사나무 KWNU94334

Duchesnea indica (Andrews) Focke 뱀딸기 KWNU94376

Filipendula glaberrima (Nakai) Nakai 터리풀 KWNU97474

Geum aleppicum Jacq. 큰뱀무 KWNU94340

Malus baccata (L.) Borkh. 야광나무 KWNU94307

Potentilla chinensis Ser. 딱지꽃 KWNU94342
Appendix 1. Continued.

\begin{tabular}{|c|}
\hline Scientific name/Korean name/Voucher number \\
\hline Potentilla cryptotaeniae Maxim. 물양지꽃 KWNU97459 \\
\hline Potentilla fragarioides L. 양지꽃 KWNU94343 \\
\hline Potentilla freyniana Bornm. 세잎양지꽃 KWNU96927 \\
\hline Prunus armeniaca L. 살구나무(재) KWNU97457 \\
\hline Prunus japonica var. nakaii (H.Lév.) Rehder 이스라지 KWNU97439 \\
\hline Prunus padus L. 귀룽나무 KWNU94345 \\
\hline Prunus persica (L.) Stokes 복사나무(재) KWNU94346 \\
\hline Prunus salicina Lindl. 자두나무(재) KWNU94347 \\
\hline Prunus sargentii Rehder 산벚나무 KWNU96498 \\
\hline Pyrus ussuriensis Maxim. ex Rupr. 산돌배 KWNU97451 \\
\hline Rosa multiflora Thunb. 찔레꽃 KWNU95935 \\
\hline Rubus crataegifolius Bunge 산딸기 KWNU95944 \\
\hline Rubus parvifolius L. 멍석딸기 KWNU94466 \\
\hline Rubus phoenicolasius Maxim. 곰딸기 KWNU95938 \\
\hline Rubus pungens Cambess. 줄딸기 KWNU96507 \\
\hline Sanguisorba officinalis L. 오이풀 KWNU96485 \\
\hline Sorbaria sorbifolia (L.) A.Braun 쉬땅나무 $K W N U 96513$ \\
\hline Sorbus commixta Hedl. 마가목(재) KWNU94277 \\
\hline Spiraea chamaedryfolia L. 인가목조팝나무 KWNU97466 \\
\hline Spiraea fritschiana C.K.Schneid. 참조팝나무 KWNU94470 \\
\hline Spiraea prunifolia f. simpliciflora Nakai 조팝나무 KWNU95713 \\
\hline Spiraea pubescens Turcz. 아구장나무 KWNU94375 \\
\hline Spiraea trichocarpa Nakai 갈기조팝나무 KWNU94335 \\
\hline Stephanandra incisa (Thunb.) Zabel 국수나무 KWNU94377 \\
\hline Fabaceae 콩과 \\
\hline $\begin{array}{l}\text { Amphicarpaea bracteata subsp. edgeworthii (Benth.) H.Ohashi 새콩 } \\
K W N U 94336\end{array}$ \\
\hline Chamaecrista nomame (Makino) H.Ohashi 차풀 KWNU94378 \\
\hline $\begin{array}{l}\text { Glycine max subsp. soja (Siebold \& Zucc.) H.Ohashi 돌콩 } \\
\text { KWNU94337 }\end{array}$ \\
\hline $\begin{array}{l}\text { Hylodesmum podocarpum subsp. oxyphyllum (DC.) H.Ohashi \& } \\
\text { R.R.Mill 도둑놈의갈고리 } K W N U 95931\end{array}$ \\
\hline Kummerowia striata (Thunb.) Schindl. 매듭풀 KWNU95961 \\
\hline Lathyrus davidii Hance 활량나물 KWNU96922 \\
\hline Lespedeza bicolor Turcz. 싸리 KWNU97222 \\
\hline Lespedeza cuneata (Dum.Cours.) G.Don 비수리 KWNU94380 \\
\hline Lespedeza cyrtobotrya Miq. 참싸리 KWNU94330 \\
\hline Lespedeza maximowiczii C.K.Schneid. 조록싸리 KWNU94368 \\
\hline Maackia amurensis Rupr. 다릅나무 KWNU95970 \\
\hline Pueraria lobata (Willd.) Ohwi 칡 KWNU94331 \\
\hline Robinia pseudoacacia L. 아까시나무(재) KWNU94369 \\
\hline Sophora flavescens Aiton 고삼 KWNU94284 \\
\hline Trifolium repens L. 토끼풀 KWNU94321 \\
\hline Vicia amurensis Oett. 벌완두 KWNU95454 \\
\hline Vicia chosenensis Ohwi 노랑갈퀴 KWNU94322 \\
\hline
\end{tabular}


Appendix 1. Continued.

\begin{tabular}{l}
\hline \hline Scientific name/Korean name/Voucher number \\
Vicia unijuga A.Braun 나비나물 KWNU95456 \\
Vigna angularis var. nipponensis (Ohwi) Ohwi \& H.Ohashi 새팥 \\
KWNU95930
\end{tabular}

Oxalidaceae 괭이밥과

Oxalis stricta L. 선괭이밥 KWNU97465

Geraniaceae 쥐손이풀과

Geranium sibiricum L. 쥐손이풀 KWNU95953

Geranium thunbergii Siebold ex Lindl. \& Paxton 이질풀 KWNU94371

\section{Euphorbiaceae 대극과}

Acalypha australis L. 깨풀 KWNU94323

Euphorbia supina Raf. 애기땅빈대 KWNU97464

Securinega suffruticosa (Pall.) Rehder 광대싸리 KWNU94906 ${ }^{\star}$

\section{Rutaceae 운향과}

Phellodendron amurense Rupr. 황벽나무 KWNU97442

Simaroubaceae 소태나무과

Picrasma quassioides (D.Don) Benn. 소태나무 KWNU94449

Anacardiaceae 옻나무과

Rhus chinensis Mill. 붉나무 KWNU94907

Toxicodendron trichocarpum (Miq.) Kuntze 개옻나무 KWNU94841

Aceraceae 단풍나무과

Acer mandshuricum Maxim. 복장나무 KWNU94843

Acer pictum var. mono (Maxim.) Maxim. ex Franch. 고로쇠나무 KWNU94836

Acer pseudosieboldianum (Pax) Kom. 당단풍나무 KWNU94851 ^

Acer tataricum subsp. ginnala (Maxim.) Wesm. 신나무 KWNU94842

Acer triflorum Kom. 복자기 KWNU95429^

\section{Balsaminaceae 봉선화과}

Impatiens noli-tangere $\mathrm{L}$. 노랑물봉선 KWNU97478

Impatiens textorii Miq. 물봉선 KWNU97479

Celastraceae 노박덩굴과

Celastrus orbiculatus Thunb. 노박덩굴 KWNU94280^

Euonymus alatus (Thunb.) Siebold 화살나무 KWNU95945`

Euonymus alatus f. ciliato-dentatus (Franch. \& Sav.) Hiyama 회잎나 무 KWNU94976

Euonymus pauciflorus Maxim. 회목나무 KWNU94845*

Tripterygium regelii Sprague \& Takeda 미역줄나무 KWNU96492 ${ }^{\star}$

Rhamnaceae 갈매나무과

Rhamnus davurica Pall. 갈매나무 KWNU94350^

Rhamnus yoshinoi Makino 짝자래나무 KWNU97484

Vitaceae 포도과

Ampelopsis brevipedunculata f. ciliata (Nakai) T.B.Lee 털개머루 KWNU94989

Parthenocissus tricuspidata (Siebold \& Zucc.) Planch. 담쟁이덩굴 KWNU94847

Vitis amurensis Rupr. 왕머루 KWNU97233
Appendix 1. Continued.

Scientific name/Korean name/Voucher number

Vitis coignetiae Pulliat ex Planch. 머루 KWNU94852

\section{Tiliaceae 피나무과}

Corchoropsis tomentosa (Thunb.) Makino 수까치깨 KWNU96491

Tilia amurensis Rupr. 피나무 KWNU94848

Tilia mandshurica Rupr. \& Maxim. 찰피나무 KWNU94849

Violaceae 제비꽃과

Viola acuminata Ledeb. 졸방제비꽃 KWNU94904

Viola albida var. chaerophylloides (Regel) F.Maek. ex H.Hara 남산제 비꽃 KWNU94970

Viola arcuata Blume 콩제비꽃 KWNU94830

Viola collina Besser 둥근털제비꽃 KWNU94948

Viola keiskei Miq. 잔털제비꽃 KWNU95964

Viola mandshurica W.Becker 제비꽃 KWNU94853

Viola orientalis (Maxim.) W.Becker 노랑제비꽃 KWNU96935

Viola phalacrocarpa Maxim. 털제비꽃 KWNU94460

Viola rossii Hemsl. 고깔제비꽃 KWNU94829

Viola tokubuchiana var. takedana (Makino) F.Maek. 민둥뫼제비꽃 KWNU94975

Viola variegata Fisch. ex Link 알록제비꽃 KWNU94854

Cucurbitaceae 박과

Schizopepon bryoniifolius Maxim. 산외 KWNU94831

\section{Onagraceae 바늘꽃과}

Circaea cordata Royle 쇠털이슬 KWNU94855

Circaea lutetiana subsp. quadrisulcata (Maxim.) Asch. \& Magnus 말 털이슬 KWNU95390

Ludwigia prostrata Roxb. 여뀌바늘 KWNU95389

Oenothera biennis L. 달맞이꽃 KWNU94364

Alangiaceae 박쥐나무과

Alangium platanifolium var. trilobum (Miq.) Ohwi 박쥐나무 KWNU94988

\section{Cornaceae 충충나무과}

Cornus controversa Hemsl. 층층나무 KWNU94856

Cornus officinalis Siebold \& Zucc. 산수유(재) KWNU95946

Cornus walteri Wangerin 말채나무 KWNU94362

Araliaceae 두릅나무과

Aralia elata (Miq.) Seem. 두릅나무 KWNU94908

Eleutherococcus sessiliflorus (Rupr. \& Maxim.) S.Y.Hu 오갈피나무 KWNU97489

Kalopanax septemlobus (Thunb.) Koidz. 음나무 KWNU95269

Apiaceae 산형과

Angelica polymorpha Maxim. 궁궁이 KWNU94833

Anthriscus sylvestris (L.) Hoffm. 전호 KWNU94909^

Cryptotaenia japonica Hassk. 파드득나물 KWNU96923 ${ }^{\star}$

Ostericum grosseserratum (Maxim.) Kitag. 신감채 KWNU96940

Ostericum sieboldii (Miq.) Nakai 묏미나리 KWNU94858 
Appendix 1. Continued.

\begin{tabular}{l}
\hline \hline \multicolumn{1}{c}{ Scientific name/Korean name/Voucher number } \\
\hline Peucedanum terebinthaceum (Fisch. ex Trevir.) Fisch. ex Turcz. 기름 \\
나물 KWNU97126^ \\
Pimpinella brachycarpa (Kom.) Nakai 참나물 $K W N U 97450^{\star}$ \\
Sanicula chinensis Bunge 참반디 KWNU97458 \\
Ericaceae 진달래과 \\
Pyrola japonica Klenze ex Alef. 노루발 KWNU94866 \\
Rhododendron mucronulatum Turcz. 진달래 KWNU94867 \\
Rhododendron mucronulatum var. ciliatum Nakai 털진달래 \\
KWNU94980 \\
Rhododendron schlippenbachii Maxim. 철쭉 KWNU95274 \\
Rhododendron yedoense f. poukhanense (H.Lév.) Sugim. ex T.Yamaz. \\
산철쭉 KWNU94984 \\
Vaccinium hirtum var. koreanum (Nakai) Kitam. 산앵도나무 \\
KWNU96934
\end{tabular}

Primulaceae 앵초과

Lysimachia clethroides Duby 큰까치수염 KWNU94939

Lysimachia vulgaris var. davurica (Ledeb.) R.Knuth 좁쌀풀 KWNU94951

\section{Symplocaceae 노린재나무과}

Symplocos sawafutagi Nagam. 노린재나무 KWNU94974*

\section{Oleaceae 물푸레나무과}

Fraxinus rhynchophylla Hance 물푸레나무 KWNU97234

Ligustrum obtusifolium Siebold \& Zucc. 쥐똥나무 KWNU95547

Syringa pubescens subsp. patula (Palib.) M.C.Chang \& X.L.Chen 털 개회나무 $K W N U 95425$

Syringa reticulata (Blume) H.Hara 개회나무 $K W N U 94828^{\star}$

Apocynaceae 협죽도과

Cynanchum ascyrifolium (Franch. \& Sav.) Matsum. 민백미꽃 KWNU96936

Cynanchum paniculatum (Bunge) Kitag. ex H.Hara 산해박 KWNU95956 ${ }^{\star}$

Cynanchum wilfordii (Maxim.) Hemsl. 큰조롱 KWNU94367^

Metaplexis japonica (Thunb.) Makino 박주가리 KWNU94940

Rubiaceae 꼭두서니과

Galium dahuricum Turcz. ex Ledeb. 큰잎갈퀴 KWNU94953

Galium trifloriforme Kom. 개선갈퀴 KWNU94941

Galium verum L. 솔나물 KWNU94942

Rubia argyi (H.Lév. \& Vaniot) H.Hara ex Lauener 꼭두서니 KWNU96488

Rubia cordifolia L. 갈퀴꼭두서니 KWNU97224

\section{Convolvulaceae 메꽃과}

Calystegia pubescens Lindl. 메꽃 KWNU97235

Cuscuta australis R.Br. 실새삼 KWNU94960

Cuscuta japonica Choisy 새삼 KWNU95410

Ipomoea purpurea (L.) Roth 둥근잎나팔꽃 KWNU95411

Boraginaceae 지치과

Brachybotrys paridiformis Maxim. ex Oliv. 당개지치 KWNU97452
Appendix 1. Continued.

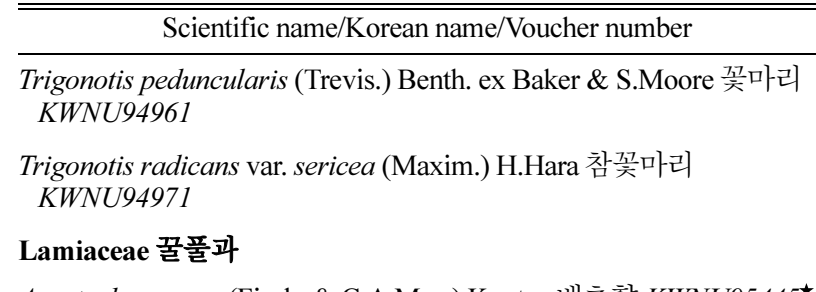

Agastache rugosa (Fisch. \& C.A.Mey.) Kuntze 배초향 KWNU95445` Amethystea caerulea L. 개차즈기 KWNU95447

Clinopodium chinense var. parviflorum (Kudô) H.Hara 층층이꽃 KWNU96939

Clinopodium micranthum (Regel) H.Hara 두메층층이 KWNU94281

Elsholtzia ciliata (Thunb.) Hyl. 향유 KWNU94962 ${ }^{\star}$

Isodon excisus (Maxim.) Kudô 오리방풀 KWNU94963

Isodon inflexus (Thunb.) Kudô 산박하 KWNU94969

Isodon japonicus (Burm.f.) H.Hara 방아풀 KWNU95963`

Lamium album subsp. barbatum (Siebold \& Zucc.) Mennema 광대수 염 KWNU94979^

Leonurus japonicus Houtt. 익모초 KWNU95450^

Leonurus macranthus Maxim. 송장풀 KWNU95958

Lycopus lucidus Turcz. ex Benth. 쉽싸리 KWNU94462

Meehania urticifolia (Miq.) Makino 벌깨덩굴 KWNU94887^

Mentha arvensis var. piperascens Malinv. ex Holmes 박하 KWNU97472

Mosla scabra (Thunb.) C.Y.Wu \& H.W.Li 들깨풀 KWNU94991

Prunella vulgaris subsp. asiatica (Nakai) H.Hara 꿀풀 KWNU94964

Salvia chanryoenica Nakai 참배암차즈기 KWNU95448*

Stachys riederi var. japonica (Miq.) H.Hara 석잠풀 KWNU94749

Solanaceae 가지과

Solanum americanum Mill. 미국까마중 KWNU97220

Scrophulariaceae 현삼과

Melampyrum roseum Maxim. 꽃며느리밥풀 KWNU94672

Phtheirospermum japonicum (Thunb.) Kanitz 나도송이풀 KWNU94676

Scrophularia alata A.Gray 개현삼 KWNU95929

Phrymaceae 파리풀과

Phryma leptostachya var. oblongifolia (Koidz.) Honda 파리풀 KWNU94675

Plantaginaceae 질경이과

Plantago asiatica L. 질경이 KWNU94697

Caprifoliaceae 인동과

Lonicera japonica Thunb. 인동덩굴 KWNU94351

Lonicera maackii (Rupr.) Maxim. 괴불나무 KWNU94487

Lonicera praeflorens Batalin 올괴불나무 KWNU94938

Sambucus williamsii Hance 딱총나무 KWNU94977

Viburnum carlesii Hemsl. 분꽃나무 KWNU94965

Viburnum opulus var. calvescens (Rehder) H.Hara 백당나무 KWNU94451 
Appendix 1. Continued.

\begin{tabular}{l}
\hline \hline \multicolumn{1}{c}{ Scientific name/Korean name/Voucher number } \\
\hline Weigela florida (Bunge) A.DC. 붉은병꽃나무 $K W N U 94885^{\star}$ \\
Weigela subsessilis (Nakai) L.H.Bailey 병꽃나무 $K W N U 96928^{\star}$ \\
Adoxaceae 연복초과 \\
Adoxa moschatellina L. 연복초 $K W N U 94729$ \\
Valerianaceae 마타리과 \\
Patrinia scabiosifolia Fisch. ex Trevir. 마타리 KWNU95414 \\
Patrinia villosa (Thunb.) Juss. 뚝갈 KWNU95952 \\
Valeriana fauriei Briq. 쥐오줌풀 $K W N U 95967$ \\
Campanulaceae 초롱꽃과 \\
Adenophora divaricata Franch. \& Sav. 넓은잔대 $K W N U 94738$ \\
Adenophora racemosa J.K.Lee \& S.T.Lee 외대잔대 $K W N U 95933$ \\
Adenophora remotiflora (Siebold \& Zucc.) Miq. 모시대 KWNU94748 \\
Adenophora triphylla (Thunb.) A.DC. 층층잔대 $K W N U 96926$ \\
Asyneuma japonicum (Miq.) Briq. 영아자 $K W N U 94747$ \\
Campanula punctata Lam. 초롱꽃 KWNU94740 \\
Platycodon grandiflorus (Jacq.) A.DC. 도라지 $K W N U 94744$
\end{tabular}

\section{Asteraceae 국화과}

Adenocaulon himalaicum Edgew. 멸가치 KWNU97242

Ainsliaea acerifolia Sch.Bip. 단풍취 KWNU94657

Ambrosia artemisiifolia L. 돼지풀 KWNU97470

Ambrosia trifida L. 단풍잎돼지풀 KWNU94656

Artemisia annua L. 개똥쑥 KWNU94690

Artemisia capillaris Thunb. 사철쑥 KWNU95954

Artemisia japonica Thunb. 제비쑥 KWNU94728

Artemisia keiskeana Miq. 맑은대쑥 KWNU94717

Artemisia lancea Vaniot 뺑쑥 KWNU97483

Artemisia sacrorum var. iwayomogi (Kitam.) M.S.Park \& G.Y.Chung 더위지기 $K W N U 94733^{\star}$

Artemisia stolonifera (Maxim.) Kom. 넓은잎외잎쑥 KWNU95002 Aster ageratoides Turcz. 까실쑥부쟁이 KWNU94716

Aster iinumae Kitam. ex H.Hara 버드쟁이나물 KWNU94725

Aster scaber Thunb. 참취 KWNU94319

Aster tataricus L.f. 개미취 $K W N U 95966^{\star}$

Aster yomena (Kitam.) Honda 쑥부쟁이 KWNU94673

Atractylodes ovata (Thunb.) DC. 삽주 KWNU94695^

Bidens bipinnata L. 도깨비바늘 KWNU95339*

Bidens frondosa L. 미국가막사리 KWNU94694

Bidens tripartita L. 가막사리 KWNU97119 ${ }^{\star}$

Carduus crispus L. 지느러미엉겅퀴 KWNU95971

Carpesium triste Maxim. 두메담배풀 KWNU94814

Chrysanthemum boreale (Makino) Makino 산국 KWNU96925

Chrysanthemum zawadskii var. latilobum (Maxim.) Kitam. 구절초 KWNU94797*

Cirsium japonicum var. maackii (Maxim.) Matsum. 엉겅퀴 KWNU94811
Appendix 1. Continued.

\begin{tabular}{|c|}
\hline e/Korean name/Voucher number \\
\hline Cirsium pendulum Fisch. ex DC. 큰엉겅퀴 $K W N U 94692^{\star}$ \\
\hline Conyza canadensis (L.) Cronquist 망초 KWNU95723 \\
\hline Coreopsis lanceolata L. 큰금계국(재) KWNU94693 \\
\hline $\begin{array}{l}\text { Crepidiastrum denticulatum (Houtt.) J.H.Pak \& Kawano 이고들 빼기 } \\
\text { KWNU94691 }\end{array}$ \\
\hline $\begin{array}{l}\text { Crepidiastrum sonchifolium (Maxim.) J.H.Pak \& Kawano 고들빼기 } \\
K W N U 95340^{\star}\end{array}$ \\
\hline
\end{tabular}

Erigeron annuus (L.) Pers. 개망초 KWNU94365

Eupatorium japonicum Thunb. 등골나물 KWNU94827

Galinsoga ciliata (Raf.) S.F.Blake 털별 꽃아재비 KWNU97221

Helianthus tuberosus L. 뚱딴지 (재) KWNU94714

Hieracium umbellatum L. 조밥나물 KWNU94713

Inula japonica Thunb. 금불초 $K W N U 94823^{\star}$

Ixeris polycephala Cass. 벌씀바귀 KWNU94888

Lactuca indica L. 왕고들 빼기 KWNU94711

Lactuca raddeana Maxim. 산씀바귀 KWNU94712

Lactuca triangulata Maxim. 두메고들빼기 KWNU95934

Leibnitzia anandria (L.) Turcz. 솜나물 KWNU96938

Petasites japonicus (Siebold \& Zucc.) Maxim. 머위 KWNU96505^

Picris hieracioides subsp. japonica (Thunb.) Hand.-Mazz. 쇠서나물 KWNU94994

Rudbeckia laciniata L. 삼잎국화(재) KWNU95330

Saussurea grandifolia Maxim. 서덜취 KWNU94710^

Saussurea pulchella (Fisch.) Fisch. ex Colla 각시취 KWNU95949^

Sigesbeckia orientalis subsp. pubescens (Makino) H.Koyama 털진득 찰 $\mathrm{KWNU} 95341^{\star}$

Solidago virgaurea subsp. asiatica Kitam. ex H.Hara 미역취 KWNU94724*

Symphyotrichum pilosum (Willd.) G.L.Nesom 미국쑥부쟁이 KWNU94727

Syneilesis palmata (Thunb.) Maxim. 우산나물 KWNU94723*

Synurus deltoides (Aiton) Nakai 수리취 KWNU95932

Taraxacum officinale F.H.Wigg. 서양민들레 KWNU94709

Liliaceae 백합과

Asparagus schoberioides Kunth 비짜루 KWNU94708

Barnardia japonica (Thunb.) Schult.f. 무릇 KWNU94704

Convallaria keiskei Miq. 은방울꽃 KWNU95965

Disporum smilacinum A.Gray 애기나리 KWNU95955

Heloniopsis koreana Fuse 처녀치마 KWNU94722

Hemerocallis fulva (L.) L. 원추리 KWNU97123

Hosta longipes (Franch. \& Sav.) Matsum. 비비추 KWNU97231

Lilium amabile Palib. 털중나리 KWNU94707*

Lilium lancifolium Thunb. 참나리 KWNU94464^

Lilium tsingtauense Gilg 하늘 말나리 KWNU96494

Maianthemum japonicum (A.Gray) LaFrankie 풀솜대 KWNU95941 ${ }^{\star}$

Paris verticillata M.Bieb. 삿갓나물 KWNU96506 
Appendix 1. Continued.

\begin{tabular}{l}
\hline \hline \multicolumn{1}{c}{ Scientific name/Korean name/Voucher number } \\
\hline Polygonatum humile Fisch. ex Maxim. 각시둥굴레 KWNU94705 \\
Polygonatum inflatum Kom. 퉁둥굴레 KWNU94454 \\
Polygonatum odoratum var. pluriflorum (Miq.) Ohwi 둥굴레 \\
KWNU94808 \\
Smilax nipponica Miq. 선밀나물 KWNU95928 \\
Smilax sieboldii Miq. 청가시덩굴 KWNU94720 \\
Streptopus ovalis (Ohwi) F.T.Wang \& Y.C.Tang 금강애기나리 \\
KWNU94703 \\
Veratrum maackii var. japonicum (Baker) Shimizu 여로 KWNU94809 \\
Dioscoreaceae 마과 \\
Dioscorea japonica Thunb. 참마 KWNU95403 \\
Dioscorea quinquelobata Thunb. 단풍마 KWNU94285 \\
Dioscorea tokoro Makino ex Miyabe 도고로마 KWNU94957 \\
Iridaceae 붓꽃과
\end{tabular}

Iris ensata var. spontanea (Makino) Nakai 꽃창포 KWNU94719

Iris rossii Baker 각시붓꽃 KWNU94700

\section{Juncaceae 골풀과}

Juncus decipiens (Buchenau) Nakai 골풀 KWNU94732

Juncus tenuis Willd. 길골풀 KWNU96489

\section{Commelinaceae 닭의장풀과}

Streptolirion volubile Edgew. 덩굴닭의장풀 KWNU94702

\section{Poaceae 벼과}

Achnatherum pekinense (Hance) Ohwi 나래새 KWNU94680

Agrostis clavata var. nukabo Ohwi 겨이삭 KWNU97237

Arundinella hirta (Thunb.) Tanaka 털새 KWNU97473

Arundinella hirta var. ciliata (Thunb.) Koidz. 새 KWNU97468

Bromus japonicus Thunb. 참새귀리 KWNU94893

Calamagrostis epigejos (L.) Roth 산조풀 KWNU95435

Diarrhena mandshurica Maxim. 껍질용수염 KWNU94968

Digitaria ciliaris (Retz.) Koeler 바랭이 KWNU94967

Echinochloa crus-galli (L.) P.Beauv. 돌피 KWNU94950

Eleusine indica (L.) Gaertn. 왕바랭이 KWNU94966

Elymus tsukushiensis var. transiens (Hack.) Osada 개밀 KWNU94810

Eragrostis ferruginea (Thunb.) P.Beauv. 그령 KWNU94956

Eragrostis multicaulis Steud. 비노리 KWNU94955

Festuca ovina L. 김의털 KWNU94750

Lolium multiflorum Lam. 쥐보리 KWNU94944

Melica nutans L. 왕쌀새 KWNU95942

Miscanthus sinensis var. purpurascens (Andersson) Matsum. 억새 KWNU95438

Muhlenbergia huegelii Trin. 큰쥐꼬리새 KWNU97494

Oplismenus undulatifolius (Ard.) P.Beauv. 주름조개풀 KWNU94659

Panicum bisulcatum Thunb. 개기장 KWNU94678

Panicum dichotomiflorum Michx. 미국개기장 KWNU95437

Phleum pratense L. 큰조아재비 KWNU97236
Appendix 1. Continued.

\begin{tabular}{|c|}
\hline Scientific name/Korean name/Voucher number \\
\hline Phragmites japonicus Steud. 달뿌리풀 KWNU97444 \\
\hline Setaria pumila (Poir.) Roem. \& Schult. 금강아지풀 KWNU94660 \\
\hline Setaria viridis (L.) P.Beauv. 강아지풀 KWNU94679 \\
\hline $\begin{array}{l}\text { Setaria viridis subsp. pycnocoma (Steud.) Tzvelev 수강아지풀 } \\
\text { KWNU95439 }\end{array}$ \\
\hline Araceae 천남성과 \\
\hline Arisaema amurense f. serratum (Nakai) Kitag. 천남성 KWNU94813 \\
\hline Cyperaceae 사초과 \\
\hline Carex bostrychostigma Maxim. 길뚝사초 KWNU96502 \\
\hline Carex dispalata Boott 삿갓사초 $K W N U 94429$ \\
\hline Carex forficula Franch. \& Sav. 산뚝사초 KWNU94483 \\
\hline Carex japonica Thunb. 개찌버리사초 $K W N U 94663$ \\
\hline Carex lanceolata Boott 그늘사초 KWNU94681 \\
\hline Carex maackii Maxim. 타래사초 KWNU94665 \\
\hline Carex onoei Franch. \& Sav. 바늘사초 KWNU94682 \\
\hline Carex siderosticta Hance 대사초 $K W N U 94668$ \\
\hline Cyperus amuricus Maxim. 방동사니 KWNU94954 \\
\hline Eleocharis congesta D.Don 바늘골 KWNU94421 \\
\hline Fimbristylis dichotoma (L.) Vahl 하늘지기 KWNU95379 \\
\hline Scirpus wichurae Boeck. 방울고랭이 KWNU94973 \\
\hline Orchidaceae 난초과 \\
\hline Amitostigma gracile (Blume) Schltr. 병아리난초 KWNU97475 \\
\hline Cephalanthera longibracteata Blume 은 대난초 KWNU96929 \\
\hline
\end{tabular}

